Federal Reserve Bank of Minneapolis

(JV SR125)

Research Department

ONE GRAPH

\title{
SUSTAINABLE PLANS AND DEBT
}

V. V. Chari

Federal Reserve Bank of Minneapolis
Patrick J. Kehoe*

Federal Reserve Bank of Minneapolis and University of Minnesota

*We thank an anonymous referee for very useful comments and suggestions. Both authors acknowledge support from the National Science Foundation. The views expressed herein are those of the authors and not necessarily those of the Federal Reserve Bank of Minneapolis or the Federal Reserve System. 
Running Head: Sustainable Plans and Debt

Please send correspondence to:

Before September 1, 1992

Patrick J. Kehoe, Visitor

Department of Economics

University of Chicago

Chicago, Illinois 60637

After September 1, 1992

Patrick J. Kehoe

Department of Economics

University of Pennsylvania

Philadelphia, Pennsylvania 19104 
B1 - Chari, V.V. and Kehoe, Patrick J.

B2 - Sustainable Plans and Debt

C2 - This paper presents a simple general equilibrium model of optimal fiscal policy similar to that of Lucas and Stokey (1983), except that we let the government default on its debt. We consider sustainable equilibria in which both government and private agent decision rules are required to be sequentially rational. We concentrate on trigger mechanisms which specify reversion to the Markov equilibrium after deviations by the government and show that such mechanisms cannot support equilibria with positive debt. We go on to show by way of examples that there can be more complicated trigger mechanisms which support positive debt.

B6 - J. Econ. Theory

B7 -

B8 -

C4 -

B4 - Federal Reserve Bank of Minneapolis, Minneapolis, Minnesota 55480-0291, U.S.A.; University of Pennsylvania, Philadelphia, Pennsylvania 19104, U.S.A.

Classification No(s). E61, E62 
The early literature on time consistency, developed by Kydland and Prescott [19], Calvo [8], and others, compares environments which have technologies for a government to make binding future commitments with environments which have no such technologies. The main point of this work was to show that the policies chosen in an environment without commitment may be quite different from the Ramsey policies, those chosen in an environment with commitment. Recently, however, work by Barro and Gordon [5], Stokey [25], and Chari and Kehoe [10], has shown that in environments without commitment, trigger-type mechanisms can often support the Ramsey policies. (For a discussion of trigger mechanisms, see Friedman [13], Green and Porter [17], and Fudenberg and Maskin [16].)

A key feature of the models in the recent literature is that they are repeated versions of a one-period model. Technically, these models have no state variables like capital, debt, or money that link periods. Most models of interest in macroeconomics, however, have such state variables. This paper shows that the outcomes of such trigger mechanisms in dynamic environments may be fundamentally different from the outcomes of such mechanisms in repeated environments. We concentrate on a classic problem in the time consistency literature, namely, the incentive for a government to default on debt.

In an early contribution, Prescott [22] analyzed a simple infinite horizon economy in which the government finances a given stream of expenditures by raising distorting labor taxes and by selling debt. He found that if there is no technology for making binding future commitments, the government always defaults on outstanding debt to avoid levying distorting taxes. In the equilibrium of his model, the value of government debt is zero and the government runs a continuously balanced budget. This early work presents a challenge to economists interested in explaining why governments do not default on their inherited debt. An intuitive explanation is based on a trigger mechanism: governments fear that, if they default, private agents will be less willing to lend to them in the future. If the losses incurred by the government from future borrowing difficulties outweigh the current benefits from defaulting, the government will not default.

In this paper, we explore this intuitive explanation in a formal general equilibrium model. We consider the types of mechanisms which are used in repeated models by Barro and Gordon [5], Stokey [25], and Chari and Kehoe [10], to support the Ramsey outcomes. These mechanisms specify infinite reversion to 
the limit of the finite horizon equilibrium. In our environment the analogous mechanisms specify infinite reversion to a (weak) Markov equilibrium. In this Markov equilibrium the government defaults on positive debt and accepts payments owed to it by consumers (negative debt) in order to avoid levying distorting taxes. Consumers never lend to the government but do borrow from it. The government smooths taxes as well as it can subject to the constraint that in each period it can lend but never borrow.

Our first result is that, no matter what the discount factor is, trigger mechanisms which specify reversion to this Markov equilibrium cannot support equilibria with positive debt. In particular, they cannot support Ramsey outcomes with positive debt. This result is strikingly different from the results in the existing macroeconomic literature in which such trigger mechanisms can be used to support the Ramsey outcomes. The key reason for the difference is that the existing literature considers repeated models without state variables that link periods. Our model has debt as a state variable and thus gives rise to a dynamic rather than a repeated game.

The intuition for the result that these trigger mechanisms which specify reversion to this Markov equilibrium cannot support positive debt is as follows. Suppose by way of contradiction that such trigger mechanisms produce an outcome with positive debt. Consider the date at which the debt, measured in terms of its present value at date zero, is maximal. Let the government default on the debt at this date and, for the moment, leave all policies and allocations unchanged. Now government revenues must exceed expenditures at this date, that is the government must run a surplus, since the debt is maximal at this date. Similarly the cumulated value of revenues from this date to any subsequent date must exceed the cumulated value of expenditures. Thus, the government must be a net creditor at each date after the maximal date. It turns out that the Markov equilibrium allocations maximize utility subject to the constraint that the government can lend but never borrow. Therefore, reversion to this Markov equilibrium cannot support positive debt.

The Markov equilibrium described above seems like a natural starting point for an analysis of default on government debt. In the model the government clearly has an incentive to default on positive debt and to accept negative debt. Realizing this consumers have an incentive not to lend to the government but they are 
quite willing to borrow from it. It is natural to expect that these incentives imply that government debt can be negative but never positive. Since the government is maximizing consumer's utility it is also natural to expect that the equilibrium outcomes maximize consumer utility subject to the constraints that government debt is never positive and, of course, that revenues are raised through distorting taxes. One might even speculate that in a finite horizon version of our economy that this is the unique equilibrium. It turns out that this is not true. We show by way of a two-period example that there can be multiple Markov equilibria. In the example there are two Markov equilibria. In both of them government debt is negative, but only one of them maximizes utility subject to the constraint that the government debt is never positive. It is straightforward to extend this example to a long finite or infinite horizon. We show how such multiple equilibria can be used to construct trigger mechanisms along the lines of Benoit and Krishna [6], which support positive debt in either finite or infinite horizon versions of the model.

This paper is related to a large literature in game theory on the Folk theorem for infinite horizon games. This theorem cannot be applied directly in our model since our setup differs from the standard setup in repeated games as in Fudenberg and Maskin [16] in two respects. First, in standard repeated games there are several large agents while in our model there is one large agent and a large number of competitive private agents. As we discussed in Chari-Kehoe [10], even in repeated models with competitive private agents the standard Folk theorem of Fudenberg and Maskin [16] does not hold. In such repeated models a modified version of this theorem does hold and it is similar in spirit to the modifications discussed in Fudenberg, Kreps, and Maskin [14] and Fudenberg and Levine [15] who study repeated games with a long-lived player and a sequence of short-lived players. Second, our model is not a repeated game, but rather it is a dynamic game with debt as a state variable. The quantity of debt owed by consumers affects the set of feasible outcomes. This debt is, of course, determined by past decisions. In contrast, in repeated games the history does not affect the set of feasible outcomes even if it affects equilibrium outcomes.

Related work on debt and default includes Calvo [9], Grossman and Van Huyck [18], Bulow and Rogoff [7], and Atkeson [2]. Calvo developed models which generate positive debt in equilibrium. This debt 
emerges not because of trigger strategies, but rather because there is a direct cost of default. The main focus of Calvo's work is to investigate how such costs can generate a multiplicity of equilibria which are similar to the type in our two period example. Bulow and Rogoff [7] consider a partial equilibrium model of international borrowing and lending with constant interest rates, and prove a stronger result, namely, that no equilibrium can have positive debt. Some of our arguments are related to theirs except that ours are more complicated because of general equilibrium interactions of consumer's expectations of future policies and the set of feasible current government policies. Grossman and Van Huyck and Atkeson use reputation-type arguments to support positive debt in a model of international borrowing and lending.

In this paper we will consider a deterministic economy. It will become clear that our results go through in an economy with uncertainty. This paper is organized as follows. Section 1 describes the model which is a variant of the optimal fiscal policy models of Prescott [22], Barro [4], Lucas and Stokey [20], and Persson, Persson, and Svensson [21]. Section 2 considers an environment with commitment and characterizes the resulting equilibrium, called a Ramsey equilibrium, which is a dynamic counterpart of the static equilibrium considered by Ramsey [23]. We characterize the Ramsey equilibrium as a solution to a planning problem. Section 3 considers an environment without commitment. We allow the allocation rules of consumers and policy plans of the government to depend on the whole history of past government policies. We define a sustainable equilibrium to be a set of allocation rules and policy plans that satisfy sequential rationality conditions for both the private agents and the government. Section 4 characterizes a Markov equilibrium and the set of outcomes that can be sustained by a reversion to it. We show that the Markov policies and allocations solve a certain programming problem. In Section 5 we show that no equilibrium with positive debt can be supported by reverting to the Markov equilibrium. Section 6 contains some examples that illustrate this result. In Section 7 we show that even in a two-period example there are two equilibria-a good one with a low interest rate and a bad one with a high interest rate. We show how trigger mechanisms which specify reversion to the bad equilibrium after a default can support outcomes with positive debt. Section 8 concludes. 


\section{The Economy}

Consider a simple production economy populated by a large number of identical, infinitely-lived consumers. In each period t, there are two goods: labor and a consumption good. A constant returns-to-scale technology is available to transform one unit of labor into one unit of output. The output can be used for private consumption or for government consumption. Let $\ell_{t}$ and $c_{t}$ denote the per capita levels of labor and private consumption. The per capita level of government consumption in each period, denoted $g_{t}$, is exogenously specified. Feasibility requires that

$c_{t}+g_{t}=l_{t}$

The preferences of each consumer are given by

$$
\sum_{\mathrm{t}=0}^{\infty} \beta^{\mathrm{t}} \mathrm{U}\left(\mathrm{c}_{\mathrm{t}}, \ell_{\mathrm{t}}\right)
$$

where $0<\beta<1$ and $U$ is increasing in consumption, decreasing in labor, twice differentiable, strictly concave and bounded. We assume that the endowment of leisure time is given by $\bar{\ell}$ so that $\ell \leq \bar{\ell}$ and that the utility function satisfies the Inada conditions: $\lim _{c \rightarrow 0} U_{c}(c, \ell)=\infty$ for all $\ell<\bar{\ell}$ and $\lim _{\ell \rightarrow \ell} U_{\ell}(c, \bar{l})=-\infty$ for all $c$, where $\mathrm{U}_{\mathrm{c}}$ and $\mathrm{U}_{\ell}$ denote the partial derivatives of the utility function with respect to consumption and labor respectively. In addition, we assume that consumption and leisure are normal goods.

Government consumption is financed by a proportional tax on labor income and by debt. Let $\tau_{t}$ denote the tax rate on labor income in period t. Following Lucas and Stokey [20] and Rogers [24], we allow for government debt of all maturities. Lucas and Stokey show in an environment similar to ours except that the government cannot default, that the outcomes with and without commitment to tax rates coincide if and only if the government has access to debt of all maturities. We allow for debt of all maturities because we want to focus on the time inconsistency problem caused by default and avoid complications of the time inconsistency problem caused by limiting the set of government maturities. At the beginning of period $t$, the net outstanding claims on the government are ${ }_{t-1} b=\left({ }_{t-1} b_{s}\right)_{s=t}^{\infty}$ where ${ }_{t-1} b_{s}$ is a claim to goods at time s. At time $t$, consumers buy new debt claims which result in a net debt position ${ }_{t} b$. Let $\delta_{t} \in[0,1]$ denote the default rate on government debt outstanding in period t. Here $\delta_{t}=0$ corresponds to complete repayment; $\delta_{t}=1$, to 
complete default; and $0<\delta_{\mathrm{t}}<1$, to partial default. (Think of $\delta_{\mathrm{t}}$ as a tax on debt.) Let $\mathrm{q}_{\mathrm{s}}$ be the price at time $\mathrm{t}$ of the debt claim maturing at time s. The consumer's budget constraint can then be written as

$$
c_{t}-\left(1-\tau_{t}\right) l_{t}+{ }_{t} q \cdot b=\left(1-\delta_{t}\right)_{t} q \cdot{ }_{t-1} b
$$

for $\mathrm{t}=0, \ldots, \infty$, with the initial debt given by ${ }_{-1} \mathrm{~b}$ and where here and throughout the paper we will use the notation that for any $r \geq t-1,{ }_{t} q_{r} \cdot b=\sum_{s=r+1}^{\infty}{ }_{t} q_{s} b_{r} b_{s}$. We normalize ${ }_{t} q_{t}$ to be equal to 1 for all $t$. (Notice that we assume a single default rate on outstanding debt rather than letting the default rate vary by maturity. This assumption simplifies the notation and the analysis considerably. We conjecture that allowing the default rate to vary by maturity would not alter our main results.) An allocation for consumers is a sequence $x_{=}\left(x_{t}\right)_{t=0}^{\infty}$ where $\mathrm{x}=\left(\mathrm{c}_{\mathrm{t}}, \ell_{\mathrm{t}, \mathrm{t}} \mathrm{b}\right)$. The government sets labor tax rates, default rates, and debt prices to finance an exogenous sequence of government consumption. The government's budget constraint is

$$
\tau_{\mathrm{t}} \ell_{\mathrm{t}}-\mathrm{g}_{\mathrm{t}}+{ }_{\mathrm{t}} \mathrm{q} \cdot \mathrm{t} \mathrm{b}=\left(1-\delta_{\mathrm{t}}\right)_{\mathrm{t}} \mathrm{q}_{\mathrm{t}-1} \mathrm{~b}
$$

The government policy at $\mathrm{t}$ is $\pi_{\mathrm{t}}=\left(\tau_{\mathrm{t}}, \delta_{\mathrm{t}, \mathrm{t}} \mathrm{q}\right)$ where ${ }_{\mathrm{t}} \mathrm{q}=\left(_{\textrm{t}} \mathrm{q}_{\mathrm{s}}\right)_{\mathrm{s}=\mathrm{t}+1}^{\infty}$. We assume that $\tau_{\mathrm{t}} \leq 1, \delta_{\mathrm{t}} \in[0,1]$, and for technical reasons there are bounds $d_{1}>0$ and $d_{2}<0$ such that, for all $t$ and $s,{ }_{t} b_{s} \leq d_{1}$ and ${ }_{t} b_{s} \geq d_{2}$. These bounds ensure that neither consumers nor the government will use Ponzi schemes.

\section{Commitment}

Consider an environment in which there is an institution or a commitment technology through which the government can bind itself to a particular sequence of policies once and for all at time zero. In particular, the government can commit to never defaulting on its debt. The government technology for commitment is formalized by having the government choose an infinite sequence of numbers $\pi=\left(\pi_{t}\right)_{t=0}^{\infty}$ at the beginning of time and then having consumers choose their allocations. Since the government needs to predict how consumers will respond to its policies, consumer behavior is described by rules that associate government policies with allocations. Formally, an allocation rule is a sequence of functions $f=\left(f_{t}\right)_{t=0}^{\infty}$ that maps policies into allocations. A Ramsey equilibrium is a policy $\pi$ and an allocation rule $\mathrm{f}$ that satisfy the following conditions: (i) the policy $\pi$ maximizes $\sum_{t=0}^{\infty} \beta^{t} U\left(c_{t}(\pi), \ell_{t}(\pi)\right)$ subject to

$$
\tau_{\mathrm{t}} \mathrm{l}_{\mathrm{t}}(\pi)-\mathrm{g}_{\mathrm{t}}+{ }_{\mathrm{t}} \mathrm{q} \cdot \mathrm{b}(\pi)=\left(1-\delta_{\mathrm{t}}\right)_{\mathrm{t}} \mathrm{q} \cdot \mathrm{t}_{\mathrm{t}-1} \mathrm{~b}(\pi) \text { for all } \mathrm{t}
$$


(ii) for every policy $\pi^{\prime}$, the allocation $\mathrm{f}\left(\pi^{\prime}\right)$ maximizes (1.2) subject to (1.3) and (1.4).

The allocations in a Ramsey equilibrium solve a simple programming problem called the Ramsey problem. We will let $\mathrm{R}_{\mathrm{t}}$ denote the value of the government surplus at $\mathrm{t}$; namely, $\mathrm{R}_{\mathrm{t}}=\mathrm{U}_{\mathrm{c}}\left(\tau_{\mathrm{t}} \ell_{\mathrm{t}}-\mathrm{g}_{\mathrm{t}}\right)$. The first order condition for consumers imply

$$
-\frac{U_{l}}{U_{c}}=\left(1-\tau_{t}\right) .
$$

Using this condition and feasibility, $c_{t}+g_{t}=\ell_{t}$, it follows that in any equilibrium $R_{t}=U_{c} c_{t}+U_{\ell} \ell_{t}$. We have, then,

Proposition 1 (The Ramsey Equilibrium). The consumption and labor allocations, c and $\ell$, in the Ramsey equilibrium solve the problem

subject to

$$
\max \sum_{t=0}^{\infty} \beta^{t} U\left(c_{t}, \ell_{t}\right)
$$

$$
\begin{aligned}
& c_{t}+g_{t}=l_{t} \\
& \sum_{t=0}^{\infty} \beta^{t} R_{t} \geq \min \left[0, \sum_{t=0}^{\infty} \beta^{t} U_{c}\left(c_{t}, \ell_{t}\right)_{-1} b_{t}\right]
\end{aligned}
$$

Proof. In the Ramsey equilibrium the government must satisfy its budget constraint taking as given the allocation rule $f(\pi)$. These requirements impose restrictions on the set of allocations the government can achieve by varying its policies. We claim that these restrictions are summarized by (2.3) and (2.4). We first show that these restrictions imply (2.3) and (2.4). To see that these restrictions imply (2.3) note that subtracting (1.3) from (1.4) gives (2.4). We next show that these requirements imply (2.4). Consider the allocation rule $\mathrm{f}(\pi)$. For any policy $\pi$, using the Inada conditions and the theorems of Weitzman [26] and Ekeland and Schienkman [12], the consumer's first order conditions are (2.2), and

$$
{ }_{t} q_{s}={ }_{t+1} q_{s}\left(1-\delta_{t+1}\right) \beta U_{c}\left(c_{t+1}, l_{t+1}\right) / U_{c}\left(c_{t}, l_{t}\right)
$$




$$
\lim _{t \rightarrow \infty} \beta^{t} U_{c}\left(c_{t}, \ell_{t}\right) \sum_{s=0}^{\infty}{ }_{t} q_{t+s} b_{t+s}=0
$$

Multiplying (1.3) by $\beta^{t} U_{c}\left(c_{t}, \ell_{t}\right)$ summing over t and using (2.2), (2.5), and (2.6) gives

$$
\sum_{t=0}^{\infty} \beta^{t}\left[U_{c}\left(c_{t}, l_{t}\right) c_{t}+U_{l}\left(c_{t}, l_{t}\right) \ell_{t}\right]=\left(1-\delta_{0}\right) \sum_{t=0}^{\infty} \beta^{t} U_{c}\left(c_{t}, l_{t}\right)_{-1} b_{t}
$$

Now if at an allocation the value of the initial debt, namely, $\sum \beta^{t} U_{c}\left(c_{t}, \ell_{t}\right)_{-1} b_{t}$, is positive it is optimal for the government to default by setting $\delta_{0}=1$. If it is somewhat negative it is optimal for the government to accept it by setting $\delta_{0}=0$. If the value of the initial debt is so negative that it exceeds the whole present value of government spending it is optimal for the government to accept just enough of this debt so that it can set taxes equal to zero forever. Thus, using optimality by the government, we can reduce (2.7) to (2.4). Hence the requirement that the government sets $\delta_{0}$ optimally and that it satisfy its budget constraint together with the requirement that allocations are consistent with the allocation rule $f(\pi)$ imply (2.3) and (2.4).

Next, given any allocations $c$ and $\ell$ that satisfy (2.3) and (2.4) we can construct sequences of tax rates, default rates, debt prices, and levels of debt such that these allocations are consistent with the allocation rule f and the government's budget constraints. Equation (2.4) gives the tax rates. There are a large number of ways to set the rest of the policies. To derive the debt prices recursively use (2.5) to get

$$
{ }_{\mathrm{t}} \mathrm{q}_{\mathrm{s}}=\left(1-\delta_{\mathrm{t}+1}\right)\left(1-\delta_{\mathrm{t}+2}\right) \cdots\left(1-\delta_{\mathrm{s}}\right) \beta^{\mathrm{s}-\mathrm{t}} \mathrm{U}_{\mathrm{c}}\left(\mathrm{c}_{\mathrm{s}}, \ell_{\mathrm{s}}\right) / \mathrm{U}_{\mathrm{c}}\left(\mathrm{c}_{\mathrm{t}}, \ell_{\mathrm{t}}\right)
$$

where ${ }_{t} q_{t}=1$. To derive the debt and default sequences multiply the consumer's budget constraint by $\beta^{t} U_{c}\left(c_{t}, l_{t}\right)$, sum over $t$, and use (2.2), (2.5), and (2.6) and then update a period to get

$$
\sum_{s=t+1}^{\infty} \beta^{s-t} U_{c}\left(c_{s}, l_{s}\right)\left(1-\delta_{t+1}\right) \cdots\left(1-\delta_{s}\right)_{t} b_{s}=\sum_{s=t+1}^{\infty} \beta^{s-t} R_{s}
$$

Any sequence $\delta$ and b which satisfy (2.9), debt prices which satisfy (2.8) and tax rates which satisfy (2.4) will decentralize the Ramsey consumption and labor allocations. One particular way is to set the default rate for $\delta_{t}, t \geq 1$ identically equal to zero, set the debt prices ${ }_{t} q_{s}=\beta^{s-t} U_{c}\left(c_{s}, \ell_{s}\right) / U_{c}\left(c_{t}, \ell_{t}\right)$ and the debt sequence by (2.9) with the $\delta$ 's set to zero. Notice that (2.9) pins down the present value of the debt but not its composition. So, for example, we could decentralize the Ramsey equilibrium with one period debt by letting 


$$
\mathrm{b}_{\mathrm{t}+1}=\sum_{\mathrm{s}=\mathrm{t}+1}^{\infty} \beta^{\mathrm{s}-\mathrm{t}} \mathrm{R}_{\mathrm{s}} / \mathrm{U}_{\mathrm{c}}\left(\mathrm{c}_{\mathrm{t}+1}, \ell_{\mathrm{t}+1}\right)
$$

and ${ }_{\mathrm{t}} \mathrm{b}_{\mathrm{s}}=0$ for $\mathrm{s}>\mathrm{t}+1$.

As the proof of this proposition makes clear the Ramsey equilibrium pins down only the present value of the future debt and not its composition. As Lucas and Stokey have emphasized, however, in environments without commitment the composition of the debt affects the incentives of the government in the future when it optimizes given some inherited debt. Indeed in that environment the first order conditions at any date $\mathrm{t}$ will be affected by the composition of the debt. We will study such an environment in the next section. For now, however, we can get a sense of the importance of the composition of the debt in the environment with commitment. To see this imagine solving the Ramsey problem at date 0 and suppose that, at the Ramsey allocations, the present value of the initial debt is negative. The first order conditions at date $t$ would be

$$
\mathrm{U}_{\mathrm{c}}+\mathrm{U}_{\ell}+\lambda\left[\mathrm{R}_{\mathrm{c}}+\mathrm{R}_{\ell}\right]-\lambda\left[\mathrm{R}_{\mathrm{c}}+\mathrm{R}_{\ell}\right]_{-1} \mathrm{~b}_{\mathrm{t}}=0
$$

where the partial derivatives of $U$ and $R$ are evaluated at $\left(c_{t}, l_{t}\right)$ and $\lambda$ is the Lagrange multiplier on (2.3). Now

suppose ${ }_{-1} \hat{b}$ is another debt sequence with the same present value at the original Ramsey allocations, namely $\sum_{t=0}^{\infty} \beta^{t} U_{c}\left(c_{t}, \ell_{t}\right)_{-1} \hat{b}_{t}=\sum_{t=0}^{\infty} \beta^{t} U_{c}\left(c_{t}, \ell_{t}\right)_{-1} b_{t}$

but with a different composition of debt. Clearly the original equilibrium will, typically, no longer be optimal because the first order conditions (2.11) will not be satisfied at the new debt level ${ }_{-1} \hat{b}_{t}$. Because of this feature it will be important to allow the government to issue multiperiod debt in the environment without commitment. Indeed, if we constrain the government to issue only one period debt it would constrain the set of equilibrium allocations. For an extreme example of this phenomenon, recall that Lucas and Stokey studied an environment which is the same as this one except that they did not allow default. Their main result was that if there was a rich enough maturity structure for the debt then the Ramsey equilibrium is time consistent. If, however, debt is restricted, say, to being only one period debt then, typically, the Ramsey equilibrium is not time consistent. 
For later use we will say an outcome $(\pi, \mathrm{x})$ is attainable under commitment if it satisfies the government budget constraints and $\mathrm{x}$ maximizes consumer utility at date zero subject to consumer budget constraints. From the proof of the proposition it follows immediately that an outcome is attainable under commitment if the associated allocations satisfy (2.3) and (2.7). Intuitively, this requirement captures the limits on what the government could ever hope to achieve when faced with optimizing private agents even if it could commit to suboptimal policies.

\section{No Commitment}

Consider an environment in which no commitment technologies are available to the government. Formally, the lack of commitment by the government is modeled by having the government choose policy sequentially. In each period, the government and the consumers can vary their decisions depending on the history of government policies up to the time the decision is made. At the beginning of period t, the government chooses a current policy as a function of the history $h_{t-1}=\left(\pi_{s} \mid s=0, \ldots, t-1\right)$ together with a contingency plan for setting future policies for all possible future histories. Let $\sigma_{t}\left(h_{t-1}\right)$ denote the time $t$ labor tax rate, default rate, and price of debt chosen by the government when faced with history $\mathrm{h}_{\mathrm{t}-1}$. After the government sets current policy, consumers make their decisions. Faced with a history $h_{t}=\left(h_{t-1}, \pi_{t}\right)$, consumers choose time $t$ levels of consumption, labor supply, and debt holdings, denoted $\mathrm{f}_{\mathrm{t}}\left(\mathrm{h}_{\mathrm{t}}\right)$, together with a contingency plan for choosing future allocations. (The reader may wonder why the histories do not include consumers' decisions. For a discussion of this point see Chari and Kehoe [10].)

In order to define a sustainable equilibrium, we need to explain how policy plans induce future histories. Given a history $h_{t-1}$, the policy plan $\sigma$ induces future histories by $h_{t}=\left(h_{t-1}, \sigma_{t}\left(h_{t-1}\right)\right)$ and so on. Given a history $h_{t-1}$, a continuation policy of $\sigma$ is $\left(\sigma_{t}\left(h_{t-1}\right), \sigma_{t+1}\left(h_{t-1}, \sigma_{t}\left(h_{t-1}\right)\right), \ldots\right)$. Similarly, given a history $h_{t}$ and a policy plan $\sigma$, a continuation allocation of $f$ is $\left(f_{t}\left(h_{t}\right), f_{t+1}\left(h_{t}, \sigma_{t+1}\left(h_{t}\right), \ldots\right)\right.$.

Consider the situation of the government in period t. Given some history $\mathrm{h}_{\mathrm{t}-1}$ and given that future allocations evolve according to $\mathrm{f}$, the government chooses a continuation policy that maximizes the welfare of consumers 


$$
\mathrm{V}_{\mathrm{t}}\left(\mathrm{h}_{\mathrm{t}-1} ; \sigma, \mathrm{f}\right)=\sum_{\mathrm{s}=\mathrm{t}}^{\infty} \beta^{\mathrm{s}} \mathrm{U}\left(\mathrm{c}_{\mathrm{s}}\left(\mathrm{h}_{\mathrm{s}}\right), \mathrm{l}_{\mathrm{s}}\left(\mathrm{h}_{\mathrm{s}}\right)\right)
$$

subject to

$$
\tau_{s}\left(h_{s-1}\right) \ell_{s}\left(h_{s}\right)-g_{s}+{ }_{s} q\left(h_{s-1}\right) \cdot{ }_{s} b\left(h_{s}\right)=\left(1-\delta_{s}\left(h_{s-1}\right)\right)_{s} q\left(h_{s-1}\right) \cdot{ }_{s-1} b\left(h_{s-1}\right)
$$

where for all $\mathrm{s} \geq \mathrm{t}$ the future histories are induced by $\sigma$ from $\mathrm{h}_{\mathrm{t}-1}$.

Consider next a private agent in period $t$. Given some history $h_{t}$ and given that future policies evolve according to $\sigma$, a consumer chooses a continuation allocation to maximize

subject to

$$
\mathrm{W}_{\mathrm{t}}\left(\mathrm{h}_{\mathrm{t}} ; \sigma, \mathrm{f}\right)=\sum_{\mathrm{s}=\mathrm{t}}^{\infty} \beta^{\mathrm{s}} \mathrm{U}\left(\mathrm{c}_{\mathrm{s}}\left(\mathrm{h}_{\mathrm{s}}\right), \mathrm{l}_{\mathrm{s}}\left(\mathrm{h}_{\mathrm{s}}\right)\right)
$$

$$
c_{t}\left(h_{t}\right)-\left(1-\tau_{t}\right) l_{t}\left(h_{t}\right)+{ }_{t} q \cdot b\left(h_{t}\right)=\left(1-\delta_{t}\right) q_{t} \cdot{ }_{t-1} b\left(h_{t-1}\right)
$$

and, for $\mathrm{s}>\mathrm{t}$,

$$
\mathrm{c}_{\mathrm{s}}\left(\mathrm{h}_{\mathrm{s}}\right)-\left(1-\tau_{\mathrm{s}}\left(\mathrm{h}_{\mathrm{s}-1}\right)\right) \ell_{\mathrm{s}}\left(\mathrm{h}_{\mathrm{s}}\right)+{ }_{\mathrm{s}} \mathrm{q}\left(\mathrm{h}_{\mathrm{s}-1}\right) \cdot{ }_{\mathrm{s}} \mathrm{b}\left(\mathrm{h}_{\mathrm{s}}\right)=\left(1-\delta_{\mathrm{s}}\left(\mathrm{h}_{\mathrm{s}-1}\right)\right)_{\mathrm{s}} \mathrm{q}\left(\mathrm{h}_{\mathrm{s}-1}\right) \cdot{ }_{\mathrm{s}-1} \mathrm{~b}\left(\mathrm{~h}_{\mathrm{s}-1}\right)
$$

together with the debt constraints for $\mathrm{s} \geq \mathrm{t}, \mathrm{d}_{2} \leq{ }_{\mathrm{s}} \mathrm{b}\left(\mathrm{h}_{\mathrm{s}}\right) \leq \mathrm{d}_{1}$ where $\pi_{\mathrm{t}}$ is given in $\mathrm{h}_{\mathrm{t}}$ and for all $\mathrm{s}>\mathrm{t}$ the future histories are induced by $\sigma$ from $h_{\mathrm{t}}$. A sustainable equilibrium is a pair $(\sigma, \mathrm{f})$ that satisfies the following conditions: (i) Given the allocation rule $f$, for every history $h_{t-1}$ the continuation policy of $\sigma$ solves the government's problem; (ii) given a policy plan $\sigma$, for every history $h_{t}$ the continuation allocation of $f$ solves the consumer's problem. Note that in the definition we require that both the consumers and the government act optimally for every history of policies-even for histories which are not induced by the government's strategy or histories which have violated feasibility. This requirement is analogous to the requirement of perfection in a game.

\section{A Markov Equilibrium}

We begin by constructing a simple equilibrium called the Markov equilibrium. In this equilibrium, government debt is never positive. We then examine those outcomes that can be supported by trigger-type mechanisms which specify reversion to the Markov equilibrium after deviations. We characterize the set of outcomes that can be supported by these trigger mechanisms by a set of inequalities. In Sections 5 and 6 , we develop the implications of this characterization for supporting positive debt. 
A sustainable equilibrium is said to be (utility) Markov if for any pair of histories $\mathrm{h}_{\mathrm{t}-1}$ and $\hat{\mathrm{h}}_{\mathrm{t}-1}$ such that ${ }_{t-1} \mathrm{~b}\left(\mathrm{~h}_{\mathrm{t}-1}\right)={ }_{\mathrm{t}-1} \mathrm{~b}\left(\hat{\mathrm{h}}_{\mathrm{t}-1}\right),(\mathrm{i}) \mathrm{V}_{\mathrm{t}}\left(\mathrm{h}_{\mathrm{t}-1} ; \sigma, \mathrm{f}\right)=\mathrm{V}_{\mathrm{t}}\left(\hat{\mathrm{h}}_{\mathrm{t}-1} ; \sigma, \mathrm{f}\right)$, and (ii) $\mathrm{W}_{\mathrm{t}}\left(\mathrm{h}_{\mathrm{t}-1}, \pi_{\mathrm{t}} ; \sigma, \mathrm{f}\right)=\mathrm{W}_{\mathrm{t}}\left(\hat{\mathrm{h}}_{\mathrm{t}-1}, \pi_{\mathrm{t}} ; \sigma, \mathrm{f}\right)$ where $\mathrm{V}$ and $\mathrm{W}$ are defined in (3.1) and (3.3). Thus, in a Markov equilibrium the past history influences payoffs only to the extent that it changes the inherited debt structure. Note that we require that payoffs be Markov rather than that policy plans and allocation rules be Markov. A sustainable equilibrium is strategy-Markov if any two histories yielding the same debt structure result in the same policies and allocations. Clearly, any strategyMarkov equilibrium is utility-Markov. We elaborate on why we adopt this weaker definition below. (We should note that in some parts of the literature, our notion of utility Markov is referred to as weak Markov and strategy Markov is referred to as strong Markov. We think our terminology is more descriptive.)

To construct a Markov equilibrium, we proceed as follows. We define two programming problems and use them to construct a candidate equilibrium. We then develop some properties of these problems which we use to verify that the candidate equilibrium is sustainable. Consider, then, the first problem, called the Markov problem which we use to define the policy plan for the government. This problem is defined at each date $t$ and for each level of the inherited debt ${ }_{t-1} b$ as choosing allocations $\left\{\mathrm{c}_{\mathrm{s}}, \mathrm{l}_{\mathrm{s}}, \mathrm{b}\right\}_{\mathrm{s}=\mathrm{t}}^{\infty}$ and policies $\left\{\tau_{\mathrm{s}}, \delta_{\mathrm{s}}, \mathrm{q} \mathrm{q}_{\mathrm{t}}^{\infty}\right.$ to solve

$$
\mathrm{V}_{\mathrm{t}}\left(\mathrm{t}_{\mathrm{l}} \mathrm{b}\right)=\max \sum_{\mathrm{s}=\mathrm{t}}^{\infty} \beta^{\mathrm{s}-\mathrm{t}} \mathrm{U}\left(\mathrm{c}_{\mathrm{s}}, \ell_{\mathrm{s}}\right)
$$

subject to constraints (1.3) and (1.4) for $\mathrm{s}=\mathrm{t}, \ldots, \infty$ and

$$
\begin{aligned}
& -\mathrm{U}_{\ell}\left(\mathrm{c}_{\mathrm{s}}, \ell_{\mathrm{s}}\right) / \mathrm{U}_{\mathrm{c}}\left(\mathrm{c}_{\mathrm{s}}, \ell_{\mathrm{s}}\right)=\left(1-\tau_{\mathrm{s}}\right), \quad \mathrm{s}=\mathrm{t}, \ldots, \infty, \\
& { }_{\mathrm{s}} \mathrm{q}_{\mathrm{r}} \mathrm{U}_{\mathrm{c}}\left(\mathrm{c}_{\mathrm{s}}, \ell_{\mathrm{s}}\right)=\left(1-\delta_{\mathrm{s}+1}\right)_{\mathrm{s}+1} \mathrm{q}_{\mathrm{r}} \beta \mathrm{U}_{\mathrm{c}}\left(\mathrm{c}_{\mathrm{s}+1}, \ell_{\mathrm{s}+1}\right), \quad \mathrm{r} \geq \mathrm{s}+1 \text { and } \mathrm{s}=\mathrm{t}, \ldots, \infty, \\
& \mathrm{d}_{1} \leq{ }_{\mathrm{s}} \mathrm{b}_{\mathrm{r}} \leq \mathrm{d}_{2}, \quad \mathrm{r} \geq \mathrm{s}+1 \text { and } \mathrm{s}=\mathrm{t}, \ldots, \infty, \\
& \sum_{\mathrm{s}=\mathrm{r}}^{\infty} \beta^{\mathrm{s}-\mathrm{r}} \mathrm{U}\left(\mathrm{c}_{\mathrm{s}}, \ell_{\mathrm{s}}\right) \geq \mathrm{V}_{\mathrm{r}}\left({ }_{\mathrm{r}-1} \mathrm{~b}\right), \quad \mathrm{r}=\mathrm{t}+1, \ldots, \infty
\end{aligned}
$$

where in (4.5) the term $\mathrm{V}_{\mathrm{r}}\left(\mathrm{r}_{\mathrm{r}-1} \mathrm{~b}\right)$ denotes the maximized value of this same objective function at date $\mathrm{r}$. Constraints (1.3) and (1.4) are the consumer and government budget constraints, while constraints (4.2)-(4.4) are the first order conditions to the consumer's maximization problem. 
To gain some intuition for constraint (4.5), consider (4.1) at date 0 with some initial debt ${ }_{-1} \mathrm{~b}$ and the inequalities in (4.5) deleted. This problem gives both the Ramsey allocations and the Ramsey policies. To see this note that problem (4.1) contains as constraints the first order conditions of consumers and the consumer and government budget constraints. (Note that in the Ramsey problem in Proposition 1 we substituted out the policies and simplified the resulting constraints.) Let ${ }_{0} \mathrm{~b}$ be the debt inherited at date 1 from problem (4.1) at date 0 with constraint (4.5) deleted. Suppose that the value of this debt is positive. When at date 1 the government solves this problem clearly it will default on the debt and thus will not carry out the date 0 plan. Imposing constraint (4.5) on the date 0 problem ensures that the debt passed on to date 1 will be such that at that date the government will not have an incentive to deviate from the date 0 plan. Similar logic applies to other dates.

Consider next a second programming problem at date $\mathrm{t}$ which we use to define the consumer allocation rule. This problem is defined as choosing allocations $\left\{\mathrm{c}_{\mathrm{s}}, \ell_{\mathrm{s}}, \mathrm{b}\right\}_{\mathrm{s}=\mathrm{t}}^{\infty}$ and policies $\left\{\tau_{\mathrm{s}}, \delta_{\mathrm{s}, \mathrm{s}} \mathrm{q}\right\}_{\mathrm{s}=\mathrm{t}+1}^{\infty}$ given ${ }_{\mathrm{t}-1} \mathrm{~b}$ and $\pi_{\mathrm{t}}$ to solve the problem

$$
\mathrm{W}_{\mathrm{t}}\left(\mathrm{t}_{\mathrm{t}-1} \mathrm{~b}, \pi_{\mathrm{t}}\right)=\max \sum_{\mathrm{s}=\mathrm{t}}^{\infty} \beta^{\mathrm{s}-\mathrm{t}} \mathrm{U}\left(\mathrm{c}_{\mathrm{s}}, \mathrm{l}_{\mathrm{s}}\right)
$$

subject to (1.3), (4.2)-(4.4), and (4.5) and subject to (1.4) for $\mathrm{s}=\mathrm{t}+1, \ldots, \infty$. This problem imposes all the constraints of (4.1) except the government budget constraint at date $t$.

To gain some intuition for (4.6) note that in constructing a sustainable equilibrium we must define the consumer allocation rule for all histories including ones in which the government deviates. Now suppose at $t-1$ the consumers saved ${ }_{t-1} b$ and at the beginning of period t the government deviates to some policy $\pi_{t}$ which may not meet its period t budget constraint. Problem (4.6) defines the consumer's optimal allocation given that the consumer expects the government to follow the same policies as it does in problem (4.1) in all periods $s \geq t+1$. We elaborate on this connection between problems (4.1) and (4.6) below.

We use program (4.1) to construct the policy plan for the government denoted by $\sigma^{\mathrm{m}}$ and we use program (4.6) to construct the consumer allocation $\mathrm{f}^{\mathrm{m}}$. Suppose first, for simplicity, that for each value of the state variables (4.1) and (4.6) have unique solutions. Then we define $\mathrm{f}^{\mathrm{m}}$ as follows. Let $\mathrm{f}_{0}^{\mathrm{m}}\left(\mathrm{h}_{0}\right)$ be the 
allocations which solve (4.6) at $\left(_{-1} \mathrm{~b}, \pi_{0}\right)$ with ${ }_{-1} \mathrm{~b} \equiv 0$. Let $\mathrm{f}_{1}^{\mathrm{m}}\left(\mathrm{h}_{1}\right)$ solve (4.6) at $\left({ }_{0} \mathrm{~b}\left(\mathrm{~h}_{0}\right), \pi_{1}\right)$ where ${ }_{0} \mathrm{~b}\left(\mathrm{~h}_{0}\right)$ solves (4.6) at $\left(_{-1} b, \pi_{0}\right)$. Recursively, this procedure defines $\mathrm{f}_{t}^{\mathrm{m}}\left(\mathrm{h}_{\mathrm{t}}\right)$. Define $\sigma^{\mathrm{m}}$ as follows. For any history $\mathrm{h}_{\mathrm{t}-1}$, let ${ }_{t-1} b^{m}\left(h_{t-1}\right)$ be defined from the allocation rules $f^{m}$. Let $\sigma_{t}^{m}\left(h_{t-1}\right)$ be defined from the policies which solve (4.1) at ${ }_{t-1} b^{m}\left(h_{t-1}\right)$.

Suppose next that at some date $t$ with some inherited debt there is more than one solution to (4.1). We then define $\sigma_{t}^{m}\left(h_{t-1}\right)$ as follows. The history $h_{t-1}$ yields the policy $\pi_{t-1}$ which was chosen at date $t-1$. If $\pi_{\mathrm{t}-1}=\sigma_{\mathrm{t}-1}^{\mathrm{m}}\left(\mathrm{h}_{\mathrm{t}-2}\right)$ then choose the policy associated with problem (4.1) at date $\mathrm{t}-1$ while if $\pi_{\mathrm{t}-1} \neq \sigma_{\mathrm{t}-1}^{\mathrm{m}}\left(\mathrm{h}_{\mathrm{t}-1}\right)$ then make an arbitrary selection. If $\pi_{\mathrm{t}-1}=\sigma_{\mathrm{t}-1}^{\mathrm{m}}\left(\mathrm{h}_{\mathrm{t}-2}\right)$ and there is indifference at date $\mathrm{t}-1$ as well repeat the same procedure for period $\mathrm{t}-2$ and, so on. We resolve indifference about policies in defining $\mathrm{f}^{\mathrm{m}}$ in a similar fashion. It should be clear that at nodes of indifference by an agent the strategies specify the choice that would lead to the highest utility for the agent at the previous node. In order to do so we need the strategies to depend on the past histories. It is because of this need to resolve indifference in particular ways that we depart from the more typical type of Markov equilibria, namely strong or strategy Markov equilibria and instead use weak or utility Markov equilibria. We then have

Proposition 2 (A Markov Equilibrium). The policy plans and allocation rules $\left(\sigma^{\mathrm{m}}, \mathrm{f}^{\mathrm{m}}\right.$ ) form a sustainable equilibrium.

In the proof of this proposition we will use the fact that, by construction, problems (4.1) and (4.6) are recursive. That is, if problem (4.1) at $\mathrm{t}$ with some inherited debt gives a sequence of allocations $\left\{\mathrm{c}_{\mathrm{s}}, \ell_{\mathrm{s}}, \mathrm{s},\right\}_{\mathrm{s}=\mathrm{t}}^{\infty}$ then at any future date $r$ the continuation of the date $t$ allocation namely, $\left\{c_{s}, \ell_{s}, b=\right\}_{s=r}^{\infty}$, solves (4.1) at date $r$ with inherited debt ${ }_{\mathrm{r}-1} \mathrm{~b}$ specified in the solution to the date $\mathrm{t}$ problem. To see this note that the only way the continuation of the date $t$ allocations would not be chosen for the date $r$ problem was that there was some other continuation allocation which yielded higher utility from $r$ onward. But this would contradict the fact that in the date $t$ problem the allocation from $r$ onward satisfied constraint (4.5). Thus problem (4.1) is recursive. By a similar argument problem (4.6) is recursive. 
We will also use the fact that the solutions to (4.1) and (4.6) overlap in the obvious senses. The first sense of overlap is that if we solve (4.6) at some arbitrary $\left({ }_{t-1} b, \pi_{t}\right)$ then the solution to (4.6) from $t+1$ onward will coincide with the solution to (4.1) when (4.1) is started at the ${ }_{\mathrm{t}} \mathrm{b}$ given in the solution to (4.6).

The second sense of overlap is that if we consider maximizing (4.6) with respect to $\pi_{t}$ subject to the government budget constraint we will get the first element $\pi_{\mathrm{t}}$ in the solution to (4.1). That is,

$$
\mathrm{V}_{\mathrm{t}}\left(\mathrm{t}_{\mathrm{t}-1} \mathrm{~b}\right)=\max _{\pi_{\mathrm{t}}} \mathrm{W}_{\mathrm{t}}\left(\mathrm{t}_{\mathrm{t}-1} \mathrm{~b}, \pi_{\mathrm{t}}\right)
$$

subject to $\tau_{\mathrm{t}} \ell_{\mathrm{t}}+{ }_{\mathrm{t}} \mathrm{q}_{\mathrm{t}} \mathrm{b}=\mathrm{g}_{\mathrm{t}}+\left(1-\delta_{\mathrm{t}}\right)_{\mathrm{t}} \mathrm{q}_{\mathrm{t}-1} \mathrm{~b}$ where $l_{\mathrm{t}}$ and ${ }_{\mathrm{t}} \mathrm{b}$ denote the functions given in the solution to (4.6) evaluated at $\left({ }_{t-1} b, \pi_{t}\right)$.

Proof. Consider first optimality by consumers. At date $t$, given some history $h_{t}=\left(h_{t-1}, \pi_{t}\right)$, consumers maximize their utility (3.3) subject to (3.4) and (3.5) where future policies evolve according to $\sigma^{\mathrm{m}}$. The first order conditions for the consumer problem (3.3) are of the form (1.3) and (4.2)-(4.4). (Note that the transversality condition is redundant given (4.4).) Now since the solutions to (4.1) and (4.6) overlap in the first sense described above then the policies in the first order conditions (1.3) and (4.2)-(4.4) at the solution to (4.6) are $\pi_{\mathrm{t}}$ at $\mathrm{t}$ and, by the recursivity of (4.1), those generated by $\sigma^{\mathrm{m}}$ for $\mathrm{s}>\mathrm{t}$. That is, they are exactly the policies the consumer faces when solving (3.3). By construction then the allocations generated from $\mathrm{f}^{\mathrm{m}}$ are an optimal response to these policies.

Consider next optimality by the government. At date $t$ given some history $h_{t-1}$ the government chooses policies to maximize (3.1) subject to (3.2) where consumers future allocations evolve according to $\mathrm{f}^{\mathrm{n}}$. By the results of Whittle ([27], Chap. 24, Thm. 2.1) and Abreu ([1], Prop. 1) it suffices to show that no one shot deviations improve welfare. That is, we need only show that if consumers are following the allocation rule $\mathrm{f}^{\mathrm{m}}$ and that government policies from $\mathrm{t}+1$ onwards are generated from $\sigma^{\mathrm{m}}$ then there is no policy $\pi_{\mathrm{t}}$ at $\mathrm{t}$ which satisfies the government budget constraint and improves welfare. By construction of $\sigma^{\mathrm{m}}$ and $\mathrm{f}^{\mathrm{m}}$ this is equivalent to requiring that $\pi_{\mathrm{t}}=\sigma_{\mathrm{t}}^{\mathrm{m}}\left(\mathrm{h}_{\mathrm{t}-1}\right)$ solve problem (4.7) at ${ }_{\mathrm{t}-1} \mathrm{~b}={ }_{\mathrm{t}-1} \mathrm{~b}^{\mathrm{m}}\left(\mathrm{h}_{\mathrm{t}-1}\right)$. It is clear that it does by the second sense in which the problems overlap. 
In the particular case when ${ }_{t-1} b=0$, it is possible to obtain a sharp characterization of the Markov outcomes. In order to obtain this characterization, first we simplify problem (4.1). We can use the standard procedure similar to the one used in the proof of Proposition 1 to show that if some set of allocations $\left\{\mathrm{c}_{\mathrm{s}}, \ell_{\mathrm{s}}, \hat{\mathrm{b}}\right\}_{\mathrm{s}=\mathrm{t}}^{\infty}$ and policies $\left\{\tau_{\mathrm{s}}, \delta_{\mathrm{s}}, \mathrm{q}\right\}_{\mathrm{s=t}}^{\infty}$ along with $\left\{\delta_{\mathrm{s}}\right\}_{\mathrm{s}=\mathrm{t}}^{\infty}$ solve (4.1) then the allocations $\left\{\mathrm{c}_{\mathrm{s}}, \ell_{\mathrm{s}}, \mathrm{b}\right\}_{\mathrm{s}=\mathrm{t}}^{\infty}$ solve

$$
\mathrm{V}_{\mathrm{t}}\left(\mathrm{t}_{\mathrm{t}-1} \mathrm{~b}\right)=\max \sum_{\mathrm{s}=\mathrm{t}}^{\infty} \beta^{\mathrm{s}-\mathrm{t}} \mathrm{U}\left(\mathrm{c}_{\mathrm{s}}, \mathrm{l}_{\mathrm{s}}\right)
$$

subject to

$$
\begin{aligned}
& c_{s}+g_{s}=l_{s}, \quad s=t, \ldots, \infty, \\
& \sum_{s=t}^{\infty} \beta^{s-t} R_{s}=\left(1-\delta_{t}\right) \sum_{s=t}^{\infty} \beta^{s-t} U_{c}\left(c_{s}, l_{s}\right)_{t-1} b_{s}, \\
& R_{r}+\sum_{s=r+1}^{\infty} \beta^{s-r} U_{c}\left(c_{s}, \ell_{s}\right)_{r} b_{s}=\sum_{s=r}^{\infty} \beta^{s-r} U_{c}\left(c_{s}, l_{s}\right)_{r-1} b_{s}, \quad r=t, \ldots, \infty, \\
& d_{1} \leq{ }_{r} b_{s} \leq d_{2} \quad r=t, \ldots, \\
& \sum_{s=r}^{\infty} \beta^{s-r} U\left(c_{s}, \ell_{s}\right) \geq V_{r}(r-1 b) \quad r=t+1, \ldots,
\end{aligned}
$$

where ${ }_{\mathrm{r}} \mathrm{b}_{\mathrm{s}}=\left(1-\delta_{\mathrm{s}+1}\right) \cdots\left(1-\delta_{\mathrm{s}}\right)_{\mathrm{r}} \hat{\mathrm{b}}_{\mathrm{s}}$. Notice that, as mentioned after the proof of Proposition 1 , in terms of characterizing the constraint set at $\mathrm{t}$ there is no loss in setting the default rate from $\mathrm{s} \geq \mathrm{t}+1$ to zero. Thus the Markov problem simplifies to choosing allocations $\left\{\mathrm{c}_{\mathrm{s}}, \mathrm{l}_{\mathrm{s}}, \mathrm{b}\right\}_{\mathrm{s}=\mathrm{t}}^{\infty}$ and the initial default rate $\delta_{\mathrm{t}}$ to solve (4.8). Given any solution to this problem, it is clear that we can construct policies from the consumer's first order conditions so that the allocations and policies solve problem (4.1).

It should be clear that if the value of the debt at the optimal allocations is strictly positive than it is also optimal to default completely by setting $\delta_{\mathrm{t}}=1$. This same result holds at $\mathrm{t}+1, \mathrm{t}+2$, and so on. Therefore, it follows that the solution to (4.8) must satisfy the condition that at all future dates, the value of the debt at the optimal allocations must be nonpositive. Now multiplying (4.11) by $\beta^{\mathrm{s}-\mathrm{r}}$ and summing from $r$ to infinity and using the fact at an optimal allocation the value of the debt is always nonpositive we obtain

$$
\sum_{s=r}^{\infty} \beta^{s-r} R_{s}=\sum \beta^{s-r} U_{c}\left(c_{s}, l_{s}\right)_{s-1} b_{r} \leq 0, \quad r=t+1, \ldots, \infty,
$$


namely that the present value of the government's surpluses is nonpositive at all future dates. Note that (4.14) is a necessary condition for the continuation allocations from any history of the Markov equilibrium. We use the necessity of (4.14) repeatedly in what follows.

We now turn to the characterization of the Markov allocation when ${ }_{t-1} b=0$. In this case, it turns out that the allocations which solve (4.8) solve the following programming problem

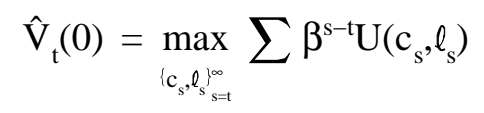

subject to

$$
\begin{aligned}
& c_{s}+g_{s}=\ell_{s} \quad \text { for } s=t, \ldots, \infty, \\
& \sum_{s=t}^{\infty} \beta^{s} R_{s} \geq 0, \\
& \sum_{s=r}^{\infty} \beta^{s} R_{s} \leq 0 \quad \text { for } r=t+1, \ldots, \infty .
\end{aligned}
$$

The essential difference between problems (4.8) and (4.15) is that constraint (4.13) is replaced by (4.18) which requires that the present value of the government's surplus be nonpositive at all future dates. The other inessential differences are that we have used optimality of the choice of $\delta_{t}$ to reduce (4.10) to (4.17) and that in problem (4.15) the debt has been substituted out as a choice variable and thus we have dropped the transition equation for debt (4.11). Note that, except for constraint (4.18), this problem is the same as the programming problem in Lucas and Stokey [20].

In the Appendix we show

Proposition 4. Suppose that for some history $h_{t-1}$, the inherited debt $t_{t-1} b\left(h_{t-1}\right)=0$. Then, there exists a debt sequence ${ }_{t} b,{ }_{t+1} b, \ldots$, such that the allocations which solve problem (4.15) also solve problem (4.8).

The construction of the debt sequence we use in the proof is similar to the one in Lucas and Stokey [20]. 


\section{Revert-to-Markov Equilibria}

We can use the Markov equilibrium of Section 4 to help characterize other possible sustainable outcomes. To characterize such outcomes, we use a modified version of the Markov equilibrium, which we call the revert-to-Markov equilibria. (These equilibria are the natural competitive analogues of the trigger-strategy equilibria of repeated games which specify reversion to the one-shot Nash equilibrium.) For an arbitrary sequence $(\pi, \mathrm{x})$, define the revert-to-Markov plans as follows. Consider first the allocation rules. For any history $h_{t}$, these plans specify the allocation $x_{t}$ given by $\mathrm{x}$ if the tax rates $\left(\pi_{0}, \ldots, \pi_{t-1}\right)$ have been chosen according to $\pi$. If they have not, then revert to the Markov allocation rules in the following sense: Suppose the first deviation, to policy $\hat{\pi}_{\mathrm{t}}$, occurs at date $\mathrm{t}$. Then the allocation rules at date $\mathrm{t}$ are given by the solution to (4.6) at $\left({ }_{t-1} b, \hat{\pi}_{t}\right)$ where ${ }_{t-1} b$ is given from $x$. For any policy $\pi_{t+1}$ the allocation rules at date $t+1$ are given by the solution to (4.6) at $\left(\mathrm{b}_{\mathrm{t}}^{\mathrm{m}}\left(\mathrm{h}_{\mathrm{t}}\right), \pi_{\mathrm{t}+1}\right)$ where ${ }_{\mathrm{t}} \mathrm{b}^{\mathrm{m}}\left(\mathrm{h}_{\mathrm{t}}\right)$ is the solution to (4.6) at $\left.{ }_{\mathrm{t}-1} \mathrm{~b}, \hat{\pi}_{t}\right)$. Allocation rules for all future dates are defined recursively. We define the reversion policy rules for the government analogously. We then have

Proposition 5 (A Set of Sustainable Outcomes). An arbitrary sequence $(\pi, \mathrm{x})$ can be supported by reverting to the Markov plans if and only if (i) $(\pi, \mathrm{x})$ is attainable under commitment and (ii) for every $\mathrm{t}$ the following inequality holds:

$$
\sum_{s=t}^{\infty} \beta^{s} U\left(c_{s}, \ell_{s}\right) \geq V_{t}(t-1)
$$

Proof. Suppose some arbitrary sequence $(\pi, \mathrm{x})$ satisfies conditions (i) and (ii). We show that the associated revert-to-Markov plans constitute a sustainable equilibrium. Consider histories under which there have been no deviations from $\pi$ before time t. By condition (i), $\mathrm{x}$ is optimal for consumers at date zero when they are faced with $\pi$, and thus it is clear that the continuation of $\mathrm{x}$ is optimal for consumers at date $\mathrm{t}$ when they are faced with the continuation of $\pi$. Consider the situation of the government. When it is confronted with revert-to-Markov allocation rules and given the fact that it will follow Markov policies from $t+1$ on, the best 
one-shot deviation for the government is simply the Markov policy at t. Thus, using (4.7), condition (5.1) guarantees that the government's plans are optimal for such histories.

Consider now histories for which there has been a deviation at or before time t. The plans for the consumers and the government specify the Markov plans from then on. By the same argument as in Proposition 2, these plans are optimal.

We now turn to our main result. To prove this result, we assume that the value of the (negative) surplus generated with zero taxes is uniformly bounded across different levels of government spending. Note that with zero taxes the surplus $R_{t}=U_{c}\left(\tau_{t} \ell_{t}-g_{t}\right)$ reduces to $R_{t}=-g_{t} U_{c}$. Let $c\left(g_{t}\right)$ and $\ell\left(g_{t}\right)$ maximize utility subject to the resource constraint $c_{t}+g_{t}=l_{t}$. We assume

$$
A=\sup \left\{g_{t} U_{c}\left(c\left(g_{t}\right), \ell\left(g_{t}\right)\right) \mid \text { all } g_{t}\right\}
$$

is finite. Under this assumption we have

Proposition 6 (Nonsupportability of Positive Debt). In any revert-to-Markov equilibrium the value of debt is nonpositive at each date.

Proof. Suppose not, that is, suppose there is some sequence of allocations $\left(c_{t}, l_{t}\right)$ and associated sequence of surpluses $\left(R_{t}\right)$ which is the outcome of a revert-to-Markov equilibrium in which the debt is strictly positive at some date. We will obtain a contradiction by showing there is a date for which deviating from the conjectured outcome to the Markov equilibrium yields higher utility then continuing with the conjectured outcome. We will accomplish this by constructing allocations which are better than the conjectured outcome but worse than the Markov outcome.

To this end recall that the transversality condition on debt holdings (2.6) implies

$$
\lim _{\mathrm{t} \rightarrow \infty} \sum_{\mathrm{s}=\mathrm{t}}^{\infty} \beta^{\mathrm{s}} \mathrm{U}_{\mathrm{c}}\left(\mathrm{c}_{\mathrm{s}}, \ell_{\mathrm{s}}\right)_{\mathrm{t}-1} \mathrm{~b}_{\mathrm{s}}=\lim _{\mathrm{t} \rightarrow \infty} \sum_{\mathrm{s}=\mathrm{t}}^{\infty} \beta^{\mathrm{s}} \mathrm{R}_{\mathrm{s}}=0 \text {. }
$$

Let $K=\max _{t} \sum_{s=t}^{\infty} \beta^{s} R_{s}$. Let this maximum be attained at date $T$, so

$$
\sum_{s=T}^{\infty} \beta^{s} R_{s} \geq \sum_{s=t}^{\infty} \beta^{s} R_{s} \quad \text { for all } t .
$$


As a first step consider simply defaulting at date $\mathrm{T}$ and continuing with the original consumption and labor allocations thereafter. Iterating on (4.11) we can show the date 0 value of the new debt sequence $\left(_{t} \hat{b}\right)$ at date $\mathrm{t} \geq \mathrm{T}$ is

$$
\sum_{s=t}^{\infty} \beta^{s} U_{c}\left(c_{s}, \ell_{s}\right)_{t-1} \hat{b}_{s}=\sum_{s=t}^{\infty} \beta^{s} R_{s}-\sum_{s=T}^{\infty} \beta^{s} R_{s}
$$

which is zero at date $\mathrm{T}$ and by (5.4) is nonpositive for $\mathrm{t} \geq \mathrm{T}$. (Note that the value of the new debt sequence is uniquely defined, though, of course, not its composition.) Thus defaulting at $\mathrm{T}$ and continuing with the old allocations clearly satisfies constraints (4.17) and (4.18) of the Markov problem. To generate a contradiction, however, we need to modify this plan.

Clearly welfare can be improved from some future date $\mathrm{T}_{1}$ onward by switching to a plan that levies smaller distorting taxes from then onward. Moreover, because the accumulated surplus is so large we can do so and still have the associated debt sequence be nonnegative. In particular, consider levying zero taxes at dates $\mathrm{T}_{1}$ and onward. The date 0 value of the loss in revenues under this plan is at most

$$
\sum_{s=T_{1}}^{\infty} \beta^{s} g_{s} U_{c}\left(c\left(g_{s}\right), \ell\left(g_{s}\right)\right)+\sum_{s=T_{1}}^{\infty} \beta^{s} R_{s} .
$$

By (5.3) for any $\varepsilon>0$ we can choose $t$ large enough so that the second term is less than $\varepsilon$ for all $\mathrm{T}_{1} \geq \mathrm{t}$. Combining this with (5.2) gives this loss in revenues is no greater than

$$
\frac{\beta^{T_{1}}}{1-\beta} A+\varepsilon
$$

Clearly then a plan of defaulting at $\mathrm{T}$, pursuing the original policies until $\mathrm{T}_{1}-1$ then switching to zero taxes after $T_{1}$ is feasible for the Markov problem in that it satisfies (4.17) and (4.18). Since it leads to higher welfare than the original equilibrium we have a contradiction.

Two remarks about this proposition are in order. First, the assumption on bounded (negative) surpluses under the zero tax plan is quite innocuous. It is satisfied, for example, whenever there are a finite number of values of government consumption. Second, under the assumption that ${ }_{-1} b \equiv 0$, the allocations under the revert-to-Markov equilibrium are unique and solve problem (4.15). To see this, note that any revert- 
to-Markov equilibrium must have nonpositive debt at each date and so, such equilibrium allocations must always satisfy (4.18). Since (4.15) maximizes utility over such allocations, the best policy for the government is simply to revert to the Markov equilibrium at date zero.

\section{Examples}

In this section, we consider four examples, which illustrate the logic behind Proposition 5. In each we let the initial debt sequence be identically zero. In such a case it follows immediately from combining the first order conditions to the Ramsey problem (2.11) with the resource constraint (2.2) that the Ramsey allocations only depend on the current level of spending $g_{t}$. In particular, the optimal surplus $R_{t}$ under the Ramsey plan only depends on the current $g_{t}$. We write the optimal surplus as $R\left(g_{t}\right)$. For concreteness let the utility function be such that the surplus under the Ramsey plan $R\left(g_{t}\right)$ is decreasing. This will be true for a variety of utility functions (see Chari and Kehoe [11]).

In Example 1, the Ramsey allocations never have positive debt and so are sustainable.

Example 1. Let $g_{t}=0$ for $t$ even and $g_{t}=\gamma$ for $t$ odd. If we interpret $g_{t}=0$ as peacetime consumption and $\mathrm{g}_{\mathrm{t}}=\gamma$ as wartime consumption then the economy starts in peacetime then alternates between wartime and peacetime. It is immediate that, under the Ramsey plan, the budget is balanced over each two-period cycle; thus,

$$
\mathrm{R}(0)+\beta \mathrm{R}(\gamma)=0
$$

Since $R\left(g_{t}\right)$ is decreasing, $R(0)$ is positive and $R(\gamma)$ is negative. The government optimally smooths distortions by running a surplus in peacetime and a deficit in wartime. For $t$ even, $\sum_{r=t}^{\infty} \beta^{t} R\left(g_{t}\right)=0$, and for $t$ odd, $\sum_{\mathrm{r}=\mathrm{t}}^{\infty} \beta^{\mathrm{t}} \mathrm{R}\left(\mathrm{g}_{\mathrm{t}}\right)=\mathrm{R}(\gamma)<0$. This implies that the Ramsey allocations solve the problem (4.15). From Proposition 4, the Ramsey allocations are sustainable. The debt issues are as follows. For $t$ even,

$$
{ }_{\mathrm{t}} \mathrm{b}_{\mathrm{t}+1}=\mathrm{R}(\gamma) / \mathrm{U}_{\mathrm{c}}(\mathrm{c}(\gamma), \ell(\gamma))<0
$$


and ${ }_{t} b_{s}=0$ for all $s \geq t+2$. For $t$ odd, ${ }_{t} b_{s}=0$ for all $s \geq t$. Thus the government sells negative debt in peacetime which exactly finances the wartime deficit and it sells zero debt in wartime. Notice that the debt issues are always nonpositive.

In the next example, a slight variant of Example 1, the Ramsey allocations are not sustainable by reversion to the Markov plan for any discount factor.

Example 2. Let $g_{t}=\gamma$ for $t$ even and $g_{t}=0$ for $t$ odd. Thus the economy starts in wartime then alternates between peacetime and wartime. Let $R\left(g_{t}\right)$ denote the surplus function for this pattern of government consumption. Under the Ramsey plan,

$$
\mathrm{R}(\gamma)+\beta \mathrm{R}(0)=0
$$

For $t$ even, $\sum_{r=t}^{\infty} \beta^{t} R\left(g_{t}\right)=R(0)>0$, and for $t$ odd, $\sum_{r=t}^{\infty} \beta^{t} R\left(g_{t}\right)=0$. Notice that the debt issues are as follows. For t even,

$$
\mathrm{b}_{\mathrm{t}+1}=\mathrm{R}(0) / \mathrm{U}_{\mathrm{c}}(\mathrm{c}(0), \ell(0))>0
$$

and ${ }_{\mathrm{t}} \mathrm{b}_{\mathrm{s}}=0$ for all $\mathrm{s} \geq \mathrm{t}+2$. For $\mathrm{t}$ odd, ${ }_{\mathrm{t}} \mathrm{b}_{\mathrm{s}}=0$ for all $\mathrm{s} \geq \mathrm{t}$. The government again runs a peacetime surplus in peacetime and a wartime deficit. Since it begins in wartime, however, at date 0 it issues positive debt which is financed by the peacetime surplus at date 1 and likewise for future dates. Suppose that at date 1 the government defaults and follows the Markov plan from then on. From Example 1, we know that such a policy gives the Ramsey allocations of that example. Thus, the original Ramsey plan is not sustainable by reversion to the Markov plan. Intuitively, after the initial war the government can optimally smooth taxes from date 1 on with the nonpositive debt of Example 1. Thus at date 1 having inherited positive debt the government gains by defaulting on the debt and suffers no loss from then on from losing the ability to issue positive debt. Of course, in equilibrium consumers anticipate the date 1 default and buy no government debt at date 0 and thus force the government to balance the budget at date 0 .

In Examples 1 and 2, government consumption follows a two-period cycle. We now consider two examples in which it follows a K-period cycle. 
Example 3. Let $\mathrm{g}_{\mathrm{t}}=\gamma_{\mathrm{k}}$ for $\mathrm{t}=\mathrm{nk}$ where $\mathrm{k}=1, \ldots, \mathrm{K}$ and the integer $\mathrm{n}>0$. Let $0=\gamma_{1}<\gamma_{2}<\ldots<\gamma_{\mathrm{k}}$. Notice that government consumption monotonically increases over each K-period cycle. Let R be decreasing under the Ramsey plan. Under this plan, the budget is balanced over each cycle so that

$$
\sum_{k=1}^{K} \beta^{k} R\left(\gamma_{k}\right)=0
$$

Since $\mathrm{R}(\cdot)$ is decreasing, we know that

$$
\sum_{k=r}^{K} \beta^{k} R\left(\gamma_{k}\right)<0, \quad \text { for } r=2, \ldots, K
$$

Hence, the Ramsey plan coincides with the Markov plan and thus is sustainable.

Example 4. Consider the same pattern of government consumption as in Example 3, except now let government consumption start at some $\gamma_{j}$. That is, let $g_{t}=\gamma_{t+J}$ for $t=1, \ldots, K-J$, and $g_{t+J}=\gamma_{k}$ for $t=n k$ where $\mathrm{k}=1, \ldots, \mathrm{K}$, and the integer $\mathrm{n} \geq 1$. Again, under the Ramsey plan, the budget is balanced over each K-period cycle:

$$
R\left(\gamma_{j}\right)+\beta R\left(\gamma_{J+1}\right)+\ldots+\beta^{K} R\left(\gamma_{J-1}\right)=0
$$

Notice that for appropriately chosen $\mathrm{J}$, the debt will be positive under the Ramsey plan. Now consider a policy similar to the one used in Example 2: default on the debt in period $\mathrm{K}-\mathrm{J}$ and follow the Markov plan from then on. Clearly, this Markov plan is simply the Ramsey plan of Example 3, and it yields higher utility than does the continuation of the original Ramsey plan. Thus, the original Ramsey plan is not sustainable.

The intuition for Examples 3 and 4 is similar to that for Examples 1 and 2. In Example 3 the economy begins in peacetime. Under commitment optimally financing of the gradually escalating war involves selling nonpositive debt. These policies is sustainable without commitment. In Example 4 the economy starts in the middle of the war and under commitment optimal financing would involve issuing positive debt during the war. Under this plan at the end of the war the government sells positive debt into the next peacetime. In this period of peace if there is no commitment the government finds it optimal to default on the inherited debt and switch to the financing pattern of Example 3 which has nonpositive debt. Thus in the period of peace the government gains from defaulting on the positive debt and, at least from this point onward, does not suffer any loss from losing the ability to sell positive debt. Thus threats which specify that it will lose this ability are 
not sufficient to deter it from defaulting. In equilibrium, consumers anticipate the government default and do not buy positive debt to begin with.

\section{Other Equilibria}

Thus far we have focused on a particular type of Markov equilibrium and equilibria which can be sustained by reverting to this Markov equilibrium. Here we discuss some other equilibria of the model.

We begin with a two period example. Let $g_{0}=0$ and $g_{1}>0$. As in Example 1 for a variety of utility functions the Ramsey plan has $\mathrm{R}_{0}<0$ and $\mathrm{R}_{1}>0$. The government runs a surplus at date 0 and the resulting negative debt allows it to run a deficit at date 1 . This plan is sustainable. To see that there is a possibility of other equilibria consider working backwards from date 1 . We will construct the equilibria in an intuitive fashion and then relate our construction to the definition of sustainable equilibrium. In period 1 given inherited debt ${ }_{0} \mathrm{~b}_{1}$ and facing policies $\tau_{1}$ and $\delta_{1}$ the consumer solves

$$
\max _{\mathrm{c}_{1}, \ell_{1}} \mathrm{U}\left(\mathrm{c}_{1}, \ell_{1}\right)
$$

subject to

$$
\mathrm{c}_{1}-\left(1-\tau_{1}\right) \ell_{1}=\left(1-\delta_{1}\right)_{0} \mathrm{~b}_{1}
$$

This problem has as a solution $\mathrm{c}_{1}=\mathrm{C}_{1}\left({ }_{0} \mathrm{~b}_{1}, \tau_{1}, \delta_{1}\right)$ and $\ell_{1}=\mathrm{L}_{1}\left({ }_{0} \mathrm{~b}_{1}, \tau_{1}, \delta_{1}\right)$. In period 1 the government, given inherited debt ${ }_{0} b_{1}$ and given that consumers will use decision rules $\mathrm{C}_{1}$ and $\mathrm{L}_{1}$, solves

$$
\max _{\tau_{1}, \delta_{1}} \mathrm{U}\left(\mathrm{C}_{1}\left({ }_{0} \mathrm{~b}_{1}, \tau_{1}, \delta_{1}\right), \mathrm{L}_{1}\left({ }_{0} \mathrm{~b}_{1}, \tau_{1}, \delta_{1}\right)\right)
$$

subject to

$$
\tau_{1} \mathrm{~L}_{1}\left({ }_{0} \mathrm{~b}_{1}, \tau_{\mathrm{t}}, \delta_{1}\right)-\mathrm{g}_{1}=\left(1-\delta_{1}\right)_{0} \mathrm{~b}_{1}
$$

This problem has as solution $\tau_{1}=\mathrm{T}_{1}\left({ }_{0} \mathrm{~b}_{1}\right)$ and $\delta_{1}=\Delta_{1}\left({ }_{0} \mathrm{~b}_{1}\right)$. At period 0 the consumer solves

$$
\max \mathrm{U}\left(\mathrm{c}_{0}, \ell_{0}\right)+\beta \mathrm{U}\left(\mathrm{c}_{1}, \ell_{1}\right)
$$

subject to

$$
\begin{aligned}
& \mathrm{c}_{0}-\left(1-\tau_{0}\right) \ell_{0}+{ }_{0} \mathrm{q}_{10} \mathrm{~b}_{1}=0 \\
& \mathrm{c}_{1}-\left(1-\tau_{1}\right) \ell_{1}=\left(1-\delta_{1}\right)_{0} \mathrm{~b}_{1} .
\end{aligned}
$$


This generates decision rules for consumption, labor supply, and debt. We focus on the decision rule for debt given by ${ }_{0} \mathrm{~b}_{1}=\mathrm{B}\left(\tau_{0,0} \mathrm{q}_{1}, \tau_{1}, \delta_{1}\right)$.

We can use these functions to construct an equilibrium. Consider first the default rule $\Delta_{1}\left({ }_{0} b_{1}\right)$. This rule is given

$$
\Delta_{1}\left(\mathrm{~b}_{0}\right)=\left\{\begin{array}{cl}
1 & \text { if }{ }_{0} \mathrm{~b}_{1}>0 \\
0 & \text { if }-\mathrm{g}<{ }_{0} \mathrm{~b}_{1} \leq 0 \\
1+\mathrm{g}_{1} / \mathrm{b}_{1} & \text { if }{ }_{0} \mathrm{~b}_{1} \leq-\mathrm{g}_{1}
\end{array}\right\} .
$$

Thus, if the debt is positive the government defaults. If the debt is not too negative the government accepts all of it. If, however, consumers owe the government more than the entire amount of government consumption at date 1 the government forgives the amount which exceeds government consumption. Notice that if the government did not forgive this portion then it would have to rebate it to consumers with distorting labor subsidies. We will concentrate on equilibria in which government debt is negative and satisfies $-\mathrm{g}<{ }_{0} \mathrm{~b}_{1} \leq$ 0 so that $\Delta_{1}\left({ }_{0} \mathrm{~b}_{1}\right)=0$.

Consider now fixing $\tau_{0}=\bar{\tau}_{0}$ and ${ }_{0} \mathrm{q}_{1}={ }_{0} \overline{\mathrm{q}}_{1}$. Denote the intersection of the consumer's debt rule $\mathrm{B}\left(\bar{\tau}_{0,0} \overline{\mathrm{q}}_{1}, \tau_{1}, 0\right)$ and the government's tax rule $\mathrm{T}_{1}\left({ }_{0} \mathrm{~b}_{1}\right)$ by ${ }_{0} \hat{\mathrm{b}}_{1}$ and $\hat{\tau}_{1}$. Substituting for $\hat{\tau}_{1}$ and setting $\delta_{1}=0$ into the consumers problem (7.5) gives allocations $\left(\hat{\mathrm{c}}_{0}, \hat{\ell}_{0}, 0, \hat{\mathrm{b}}_{1}, \hat{\mathrm{c}}_{1}, \hat{\ell}_{1}\right)$. These allocations and the policies $\left(\hat{\tau}_{1}, \hat{\delta}_{1}\right)$ satisfy consumer optimality at dates 0 and 1 given $\left(\bar{\tau}_{0,0} \overline{\mathrm{q}}_{1}\right)$ and government optimality at date 1 . Note that these are conditions which any sustainable equilibrium must satisfy given the history $\left(\bar{\tau}_{0,0} \overline{\mathrm{q}}_{1}\right)$. However, $\left(\bar{\tau}_{0,0} \overline{\mathrm{q}}_{1}\right)$ do not necessarily satisfy government optimality at date 0 . Thus the final step in the construction is to adjust these date 0 policies to solve the government's date 0 problem. Now if the intersection of the consumer's debt rule and the government's tax rule is unique for all $\left(\bar{\tau}_{0,0} \overline{\mathrm{q}}_{1}\right)$ this construction yields a unique equilibrium. The more interesting case is when the debt rule and the tax rule have multiple intersections. In this case for each $\left(\bar{\tau}_{0,0} \bar{q}_{1}\right)$ we select one of the intersections. Given this selection the construction of date 0 allocations and policies is the same. It is worth pointing out that by construction the Ramsey equilibrium is sustainable. Thus if the date 
0 policies are chosen to be the Ramsey policies, one of the intersections of the debt rule and the tax rule is associated with the Ramsey debt allocation and date 1 tax policy.

Consider constructing equilibria for the following parametric example. Let

$$
\mathrm{U}(\mathrm{c}, \ell)=\alpha_{0}+\ln \mathrm{c}-\frac{\alpha_{1}}{2} \ell^{2}
$$

With $\delta_{1}=0$ the consumer's date 1 decision rule for labor is

$$
\mathrm{L}_{1}\left(\mathrm{~b}_{0}, \tau_{1}, 0\right)=\frac{-{ }_{0} \mathrm{~b}_{1}}{\left(1-\tau_{1}\right)}+\left[\frac{\mathrm{o}^{\mathrm{b}_{1}^{2}}}{\left(1-\tau_{1}\right)^{2}}+\frac{4}{\alpha_{1}}\right]^{1 / 2} .
$$

With $-\mathrm{g}<{ }_{0} \mathrm{~b}_{1} \leq 0$, the government's decision rule for date 1 taxes $\mathrm{T}_{1}\left({ }_{0} \mathrm{~b}_{1}\right)$ is implicitly defined by

$$
0={ }_{0} b_{1}+g_{1}-\tau_{1} L_{1}\left({ }_{0} b_{1}, \tau_{1}\right)
$$

The consumer's date 0 decision rule for debt $\mathrm{B}\left(\bar{\tau}_{0,0} \overline{\mathrm{q}}_{1}, \tau_{1}, 0\right)$ is implicitly defined by the first order condition $\beta / c_{1}=q / c_{0}$ or

$$
\beta\left[\left(1-\bar{\tau}_{0}\right) \ell_{0}-{ }_{0} \overline{\mathrm{q}}_{1} \mathrm{~b}\right]={ }_{0} \overline{\mathrm{q}}_{1}\left[\left(1-\tau_{1}\right) \ell_{1}+\mathrm{b}\right]
$$

where $\ell_{1}=\mathrm{L}_{1}\left({ }_{0} \mathrm{~b}_{1}, \tau_{1}, 0\right)$ and $\left.\ell_{0}={ }_{0} \overline{\mathrm{q}}_{1} \mathrm{~b} /\left(1-\bar{\tau}_{0}\right)+\left[{ }_{0} \overline{\mathrm{q}}_{1} \mathrm{~b} /\left(1-\bar{\tau}_{0}\right)\right)^{2}+4 / \alpha_{1}\right]^{1 / 2}$.

We illustrate this construction with a numerical example. Let $\alpha_{0}=1, \alpha_{1}=0.7, \beta=0.6, \mathrm{~g}_{0}=0$, and $\mathrm{g}_{1}=1.1$. The Ramsey policies have $\tau_{0}^{\mathrm{r}}=\tau_{1}^{\mathrm{r}}=0.46,{ }_{0} \mathrm{q}_{1}^{\mathrm{r}}=1.08$, and $\delta_{1}^{\mathrm{r}}=0$. In Figure 1 we graph the consumer debt rule $\mathrm{B}(\cdot)$ against the government tax rule $\mathrm{T}_{1}(\cdot)$ with the date 0 policies $\bar{\tau}_{0}$ and ${ }_{0} \overline{\mathrm{q}}_{1}$ fixed at the Ramsey policies $\tau_{0}^{\mathrm{r}}$ and ${ }_{0} \mathrm{q}_{1}^{\mathrm{r}}$. The intersection marked 1 gives the Ramsey tax $\tau_{1}^{\mathrm{r}}$ and the Ramsey debt ${ }_{0} \mathrm{~b}_{1}^{\mathrm{r}}$. More interesting for our purposes is the other intersection marked 2. As we pointed out earlier the associated policies and allocations satisfy consumer optimality at date 0 and 1 given $\left(\tau_{0,0}^{\mathrm{r}} \mathrm{q}_{1}^{\mathrm{r}}\right)$ and government optimality at date 1 given $\left(\tau_{0}^{\mathrm{r}},{ }_{0} \mathrm{q}_{1}^{\mathrm{r}}\right)$.

The intuition for the multiple intersections is as follows. Consider first $\mathrm{T}_{1}\left({ }_{0} \mathrm{~b}_{1}\right)$. If the government inherits a large negative debt ${ }_{0} b_{1}$, it does not need to raise much revenues with taxes and chooses a small $\tau_{1}$. If the government inherits a smaller negative ${ }_{0} b_{1}$ it chooses a larger $\tau_{1}$. Thus $T_{1}(\cdot)$ is increasing in ${ }_{0} b_{1}$. Consider next $\mathrm{B}\left(\tau_{0}^{\mathrm{r}}, \mathrm{q}_{1}^{\mathrm{r}}, \tau_{1}, 0\right)$. If consumers anticipate a high tax on labor at date 1 they are poor and they 
choose low consumption and high labor supply in period 0. From their budget constraint (7.6) it follows that they save relatively more, that is, since ${ }_{0} \mathrm{~b}_{1}$ is negative they borrow less. If consumers anticipate a low tax on labor at date 1 the resulting wealth effect induces them to save less-which here means borrow more. Thus $\mathrm{B}(\cdot)$ is increasing in $\tau_{1}$. One intersection of these two functions yields the Ramsey outcome. Since both of these functions are upward sloping it is not surprising that they intersect more than once.

The final step in constructing the second equilibrium is choose $\tau_{0}$ and ${ }_{0} q_{1}$ to maximize the government's utility at date 0 . At the Ramsey policies $\tau_{0}^{\mathrm{r}}$ and ${ }_{0} \mathrm{q}_{1}^{\mathrm{r}}$, if the consumers expect the Ramsey tax rate $\tau_{1}^{\mathrm{r}}$ at date 1 their labor and debt choices together with these policies satisfy the government's budget constraint

$$
\tau_{0}^{\mathrm{r}} \ell_{0}-\mathrm{g}+{ }_{0} \mathrm{q}_{1}^{\mathrm{r}} \mathrm{b}_{1}=0
$$

Given $\tau_{0}^{\mathrm{r}}$ and ${ }_{0} \mathrm{q}_{1}^{\mathrm{r}}$ if consumers anticipate the low tax rate at date 1 , corresponding to the second intersection, they reduce $\ell_{0}$ and make ${ }_{0} \mathrm{~b}_{1}$ more negative. Thus, at the date 0 Ramsey policies, with such anticipations by consumers, the government's date 0 budget constraint would be violated. We thus vary $\tau_{0}$ and ${ }_{0} q_{1}$ and select the lower tax rate from the intersections so as to maximize the government's utility and meet its budget constraint. For our parametric example the equilibrium outcomes turn out to be $\tau_{0}=0.62,{ }_{0} q_{1}=0.73$, $\tau_{1}=0.30, \delta_{1}=0$. The utility of this equilibrium is 0.16 while that of the Ramsey equilibrium is 0.24 .

The key step in constructing the multiple equilibria for this example is showing that the functions $\mathrm{T}_{1}\left({ }_{0} \mathrm{~b}_{1}\right)$ and $\mathrm{B}\left(\tau_{0,0}^{\mathrm{r}} \mathrm{q}_{1}^{\mathrm{r}}, \tau_{1}, 0\right)$ intersect more than once. Both functions are increasing for all utility functions that are concave and for which consumption and leisure are normal goods. It should be clear that the tax rule must necessarily be increasing in the debt since a more negative debt means that the government has less need to resort to distorting taxes. The result that the debt rule is increasing follows because consumption and leisure are normal goods. It should not be surprising that a pair of increasing functions intersect more than once. Experimentation with a variety of examples suggests that multiple intersections are the rule rather than the exception. The two period setup is the simplest environment with a potential time inconsistency problem. The apparent ease with which multiple equilibria arise in this setup suggests that multiplicity of equilibria is pervasive even in finite horizon environments with sequential policymaking. It is worth pointing out that in 
this example even if we require that the government honor its debt, as in Lucas and Stokey [20], we get the same equilibrium. Note also that the better equilibrium is the Markov equilibrium of Section 4. The bad equilibrium is also a Markov equilibrium. From the construction in Section 4 it should be clear that the equilibrium there is the best of the Markov equilibria.

It is also worth pointing out that the competitive behavior of private agents plays an important role in generating this multiplicity. In our model, no single consumer perceives that his savings decision affects the future tax rate, yet the aggregate savings does indeed affect the future tax rate. To see the importance of this competitive behavior, consider instead a two period example such as ours with literally a single consumer. This consumer would realize that his saving decision determines the future tax rate. Thus the consumer can effectively pick the best point on the government's policy rule $T_{1}(b)$ and there is a unique equilibrium. More generally in a finite horizon game with only sequential moves if the best reply correspondence for each agent at each node is single-valued, it is easy to see that there is a unique subgame perfect equilibrium which can be obtained by backward induction.

Finally, note that in our example we have constructed equilibria with two types of selections from the multiple intersections. In one we chose the high intersections for all date 0 policies while in the other we chose the low intersection for all date 0 policies. More elaborate selection procedures which for some date 0 policies pick the high intersection and for others pick the low one will typically lead to more equilibria.

Now let us relate our construction to the definition of a sustainable equilibrium. A sustainable equilibrium requires that the allocation rule $\mathrm{f}_{1}\left(\pi_{0}, \pi_{1}\right)$ maximizes consumer utility for each history $\mathrm{h}_{1}=\left(\pi_{0}, \pi_{1}\right)$, where the inherited debt is given by ${ }_{0} b_{1}\left(\pi_{0}\right)$. Therefore, we have

$$
\mathrm{f}_{1}\left(\pi_{0}, \pi_{1}\right)=\left(\mathrm{C}_{1}\left(\mathrm{~b}_{0} \mathrm{~b}_{1}\left(\pi_{0}\right), \pi_{1}\right), \mathrm{L}_{1}\left(\mathrm{C}_{0} \mathrm{~b}_{1}\left(\pi_{0}\right), \pi_{1}\right)\right)
$$

The definition of sustainable equilibrium also requires that $\sigma_{1}\left(\pi_{0}\right)$ maximizes date 1 welfare subject to the government budget constraint given that consumer allocations are determined according to $\mathrm{f}_{1}$ and that inherited debt is ${ }_{0} b_{1}\left(\pi_{0}\right)$. Thus,

$$
\sigma_{1}\left(\pi_{0}\right)=\left(\mathrm { T } _ { 1 } \left({ }_{0} \mathrm{~b}_{1}\left(\pi_{0}\right), \Delta_{1}\left({ }_{0} \mathrm{~b}_{1}\left(\pi_{0}\right)\right) .\right.\right.
$$


This definition also requires that at date 0 given $\pi_{0}$ consumer decisions are optimal given the future history $\mathrm{h}_{1}=\left(\pi_{0}, \sigma_{1}\left(\pi_{0}\right)\right)$. Thus, for example, ${ }_{0} \mathrm{~b}_{1}\left(\pi_{0}\right)=\mathrm{B}\left(\pi_{0}, \sigma_{1}\left(\pi_{0}\right)\right)$. Substituting this relation into (7.15) gives

$$
\sigma_{1}\left(\pi_{0}\right)=\left(\mathrm { T } _ { 1 } \left(\mathrm{B}\left(\pi_{0}, \sigma_{1}\left(\pi_{0}\right)\right), \Delta_{1}\left(\mathrm{~B}\left(\pi_{0}, \sigma_{1}\left(\pi_{0}\right)\right)\right)\right.\right. \text {. }
$$

Solving this fixed point equation for each $\pi_{0}$ gives the function $\sigma_{1}$. In our example for each $\pi_{0}$ there are two such fixed points, one which corresponds to the higher intersection and one which corresponds to the lower intersection. Given that, say, $\hat{\sigma}_{1}$ is a fixed point to this equation the consumer period decision rules at date 0 such as the debt rule are of the form ${ }_{0} \mathrm{~b}_{1}\left(\pi_{0}\right)=\mathrm{B}\left(\pi_{0}, \hat{\sigma}_{1}\left(\pi_{0}\right)\right)$. Faced with such decision rules government optimality at date 0 gives the equilibrium policy, say $\hat{\pi}_{0}$. The equilibrium policy outcome is $\left(\hat{\pi}_{0}, \hat{\sigma}_{1}\left(\hat{\pi}_{0}\right)\right)$.

Consider now the pattern of government consumption in Example 2. Namely let it start at the high level of government consumption and then alternate between 0 and some high level of consumption. In Example 2 we showed that in the revert-to-Markov equilibrium the government's budget was balanced at date 0 and from date 1 on the government followed what would be the Ramsey policies if the economy began at date 1 with zero inherited debt. One might think that there are no other sustainable equilibria. To see that this need not be true consider the following argument. Suppose the government at date 1 inherits positive debt. One might think that the government would default on this debt and then switch to the policies given in Example 2. This is the optimal policy, of course, when consumer's allocations are given by the revert-toMarkov allocation rules. Suppose instead that if the government defaults the consumer allocation rule prescribes choosing the allocations corresponding to the lower intersection in Figure 1. For high enough discount factors the current gain from defaulting on the debt is outweighed by the losses of switching to this bad equilibrium forever. In fact for suitable parameter values positive debt can be sustained and for high enough discount factors it is even possible to sustain the Ramsey equilibrium outcomes starting at date 0 .

Notice that here we have constructed trigger equilibria along the lines of Benoit and Krishna [6]. Of course, one could use complicated triggers to construct many others. 


\section{Conclusion}

For nearly a decade economists, using differing levels of formality, have used trigger mechanism arguments for a variety of macroeconomic issues. Almost all of the formal literature, however, has analyzed these trigger arguments by using the repeated static game models similar to those used in the industrial organization literature. (See, for example, Barro and Gordon [5], and Backus and Driffill [3].) While this literature was a useful first step it is not obvious that its insights carry over to standard macromodels which are inherently dynamic. The classic papers on time consistency (including Kydland and Prescott [22]; Calvo [8]; Lucas and Stokey [20]; and Persson, Persson, and Svensson [21]) use standard general equilibrium macromodels with state variables such as capital, money, or debt. These models give rise to dynamic games and not repeated static games.

The point of this paper is to analyze the role of trigger mechanism arguments in resolving a classic problem in the time consistency literature, namely, the incentives for governments to default on their debt. We have analyzed these arguments in the simplest version of the classic general equilibrium macromodels. We have shown that in such a model reputational arguments work in a more subtle way than they do in repeated models. To see the difference between our results and those from repeated static models note that in repeated games even if there are multiple equilibria in the static game, reversion to any of the multiple equilibria supports good outcomes when there is sufficiently little discounting. In our model regardless of the discount factor reverting to the (best) Markov equilibrium cannot support the Ramsey outcome. It seems likely that trigger mechanism arguments will be even more subtle in more elaborate general equilibrium macromodels.

We also find it interesting that even in the simplest dynamic model with a finite horizon, multiple equilibria seem to be the norm rather than the exception. This feature means that even in finite horizon models the set of sustainable equilibria is large and difficult to characterize. In particular, this set cannot be characterized solely by simple backward induction arguments. We think that more complicated versions of this model with money or capital added will share similar features. In this vein notice that the multiplicity of 
equilibria in the finite horizon version of our model does not arise from the ability of the government to default on its debt.

Finally, in this paper, we have adopted the standard approach in the time consistency literature by assuming that all the commitment problems lie with the government. In a related paper, Chari and Kehoe [11], we examined an environment in which both private agents and the government can default on their debts, and we obtained quite different results. In particular, we showed that Ramsey equilibrium with positive debt can be supported with sufficiently little discounting. One reason for the difference is that in that model, private agents always default on their debts and thus government debt can only be promises to pay by the government. Since the government can default, these nonbinding promises do not constrain the policies available to the government. In contrast, in the present paper, consumers' promises to pay are enforceable and thus influence the policies available to the government. The differing results in the two papers illustrates that there is a delicate interplay between the nature of commitment technologies and the sustainability of good outcomes. It is worth exploring this interplay in future research. 


\section{Appendix}

Proof of Proposition 3. Let $\left\{c_{s}, l_{s}\right\}_{s=t}^{\infty}$ solve (4.15). We will show that there exists a debt sequence ${ }_{s-1} b$ for $\mathrm{s}=\mathrm{t}+1, \ldots$ which along with the given allocations satisfies (4.10)-(4.13). The hard part is to show that the continuation allocations to the solution of (4.15) satisfy (4.13). To show this, we will construct functions $\hat{\mathrm{V}}_{\mathrm{r}}\left({ }_{\mathrm{r}-1} \mathrm{~b}\right)$ which are at least as large as $\mathrm{V}_{\mathrm{r}}\left(\mathrm{r}_{\mathrm{r}-1} \mathrm{~b}\right)$ for all ${ }_{\mathrm{r}-1} \mathrm{~b}, \mathrm{r}=\mathrm{t}+1, \mathrm{t}+2, \ldots$, and show that the continuation allocations to (4.15) yield utility equal to $\hat{\mathrm{V}}_{\mathrm{r}}\left(\mathrm{r}_{\mathrm{r}-1} \mathrm{~b}\right)$. We use the following programming problem to construct these functions. Consider then

subject to

$$
\hat{\mathrm{V}}_{\mathrm{r}}\left(\mathrm{r}_{\mathrm{r}-1} \mathrm{~b}\right)=\max \sum_{\mathrm{s}=\mathrm{r}}^{\infty} \beta^{\mathrm{s}-\mathrm{r}} \mathrm{U}\left(\mathrm{c}_{\mathrm{s}}, \ell_{\mathrm{s}}\right)
$$

$$
\begin{aligned}
& c_{s}+g_{s}=\ell_{s} \\
& \sum_{s=r}^{\infty} \beta^{s-r} R_{s} \geq \sum_{s=r}^{\infty} \beta^{s-r} U_{c}\left(c_{s}, \ell_{s}\right)_{r-1} b_{s} \\
& \sum_{s=t}^{\infty} \beta^{s} R_{s} \leq 0, \quad t=r+1, r+2, \ldots .
\end{aligned}
$$

Using (4.14) it is clear that the constraints in problem (A1) are more relaxed than the constraints in problem (4.8). It follows that $\left.\hat{\mathrm{V}}_{\mathrm{r}(\mathrm{r}-1} \mathrm{b}\right) \geq \mathrm{V}_{\mathrm{r}}\left(\mathrm{r}_{\mathrm{r}-1} \mathrm{~b}\right)$ for all ${ }_{\mathrm{r}-1} \mathrm{~b}$. So we are done if we can construct a debt sequence satisfying (4.10)-(4.12) which together with the allocations solving (4.15) yields the same utility as (A1) at dates $r=t+1, t+2, \ldots$

Consider the first order conditions to problem (4.15). Let $\mathrm{T}_{1}$ denote the first date at which (4.18) binds. Between dates $\mathrm{t}$ and $\mathrm{T}_{1}-1$ these are

$$
\left(\mathrm{U}_{\mathrm{c}}+\mathrm{U}_{\ell}\right)+\lambda\left(\mathrm{R}_{\mathrm{c}}+\mathrm{R}_{\ell}\right)=0
$$

where the derivatives of $U$ and $R$ are evaluated at $\left(c_{s}, \ell_{s}\right)$ and $\lambda$ is the Lagrange multiplier on (4.17). From the definition of $\mathrm{R}$, it follows that (A5) can be written as

$$
(1+\lambda)\left(\mathrm{U}_{\mathrm{c}}+\mathrm{U}_{\ell}\right)+\lambda\left[\mathrm{c}\left(\mathrm{U}_{\mathrm{cc}}+\mathrm{U}_{\mathrm{c \ell}}\right)+\ell\left(\mathrm{U}_{\ell \ell}+\mathrm{U}_{\mathrm{cl}}\right)\right]=0
$$

Using normality, we have that the expression in square brackets in (A6) is negative. Since $\lambda>0, U_{c}+U_{l} \geq$ 0 and, from (A5), $R_{c}+R_{l} \leq 0$. We use these facts to construct ${ }_{t} b$. Let ${ }_{t} b_{s}=0$ for $s \geq T_{1}$. For $s<T_{1}$ we 
construct ${ }_{\mathrm{t}} \mathrm{b}$ together with Lagrange multiplier $\hat{\lambda}$ for constraint $(\mathrm{A} 3)$ of problem $(\mathrm{A} 1)$ at $\mathrm{t}+1$ so that the solution to (A1) coincides with (4.15). Suppose, therefore, that these solutions coincide. Evaluating the first-order conditions for the date $t+1$ version of (A1) at the solutions to (4.15) gives

$$
\left(\mathrm{U}_{\mathrm{c}}+\mathrm{U}_{\ell}\right)+\hat{\lambda}\left(\mathrm{R}_{\mathrm{c}}+\mathrm{R}_{\ell}\right)-\hat{\lambda}\left(\mathrm{U}_{\mathrm{cc}}+\mathrm{U}_{\mathrm{cl}}\right)_{\mathrm{t}} \mathrm{b}_{\mathrm{s}}=0 .
$$

Equation (A7) can be rearranged to get

$$
\hat{\lambda}\left[b_{\mathrm{s}}-\mathrm{a}_{\mathrm{s}}\right]=\left(\mathrm{U}_{\mathrm{c}}+\mathrm{U}_{\ell}\right) /\left(\mathrm{U}_{\mathrm{cc}}+\mathrm{U}_{\mathrm{cl}}\right)
$$

where $\mathrm{a}=\left(\mathrm{R}_{\mathrm{c}}+\mathrm{R}_{\ell}\right) /\left(\mathrm{U}_{\mathrm{cc}}+\mathrm{U}_{\mathrm{c} \ell}\right)$. Next, multiply (A8) by $\beta^{\mathrm{s}} \mathrm{U}_{\mathrm{c}}$ and sum from $\mathrm{t}+1$ through $\mathrm{T}_{1}-1$ and use (A3) to uniquely define $\hat{\lambda}$ as follows

$$
\hat{\lambda}=\frac{\sum_{t+1}^{T_{1}-1} \beta^{s} U_{c}\left(U_{c}+U_{\ell}\right) /\left(U_{c c}+U_{c \ell}\right)}{\sum_{t+1}^{T_{1}-1} \beta^{s}\left[R_{s}-U_{c} a_{s}\right]} .
$$

Recall that by hypothesis, constraint (4.18) does not bind from dates $t+1$ to $T_{1}-1$. Thus, $\Sigma_{t+1}^{T_{1}-1} \beta_{s} R_{s} \leq 0$. We have already shown $R_{c}+R_{\ell} \leq 0$, and since normality implies $U_{c c}+U_{c \ell} \leq 0$, we have that $a_{s} \geq 0$ for all $\mathrm{s}$, and therefore $\hat{\lambda} \geq 0$. Then use (A8) to define ${ }_{\mathrm{t}} \mathrm{b}_{\mathrm{s}}$ for any $\mathrm{s}$ from $\mathrm{t}+1$ through $\mathrm{T}_{1}-1$. Since ${ }_{\mathrm{t}-1} \mathrm{~b}_{\mathrm{s}}={ }_{\mathrm{t}} \mathrm{b}_{\mathrm{s}}=0$ for $\mathrm{s} \geq \mathrm{T}$, the first order conditions to (4.15) and (A1) coincide for $\mathrm{s} \geq \mathrm{T}_{1}$.

We can use similar arguments to show that the continuation allocations of (4.15) also solve (A1) for $r \geq t+2$. 


\section{References}

1. Abreu, On the theory of infinitely repeated games with discounting, Econometrica 56 (1988), 383-96.

2. A. Atkeson, International lending with moral hazard and risk of repudiation, Econometrica 59 (1991), 1069-90.

3. D.B. Backus and J. Driffill, Inflation and reputation, Amer. Econ. Rev. 75 (1985), 530-38.

4. R. J. Barro, On the determination of the public debt, J. Polit. Econ. 87 (1979), 940-71.

5. R. J. Barro, D. B. Gordon, Rules, discretion and reputation in a model of monetary policy, J. Mone. Econ. 12 (1983), 101-21.

6. J. P. Benoit and V. Krishna, Finitely repeated games, Econometrica 53 (1985), 890-904.

7. J. Bulow and K. Rogoff, Sovereign debt: Is to forgive to forget?, Amer. Econ. Rev. 79 (1989), 43-50.

8. G. A. Calvo, On the time consistency of optimal policy in a monetary economy, Econometrica 46 (1978), $1411-28$.

9. ___ Servicing the public debt: The role of expectations, Amer. Econ. Rev. 78 (1988), 647-61.

10. V. V. Chari, and P. J. Kehoe, Sustainable plans, J. Polit. Econ. 98 (1990), 783-802.

11. ___ _ _Sustainable plans and mutual default," Research Department Staff Report 124, Federal Reserve Bank of Minneapolis, 1989.

12. I. Ekeland, and J. Schienkman, Transversality conditions for some infinite horizon discrete time optimization problems, Math. Oper. Res. 11, (1986), 216-229.

13. J. W. Friedman, A non-cooperative equilibrium for supergames, Rev. Econ. Stud. 38 (1971), 1-12.

14. D. Fudenberg; D. Kreps; and E. Maskin, Repeated games with long-run and short-run players, Rev. Econ. Stud. 57 (1990), 555-74.

15. D. Fudenberg, and D. Levine, Reputation and equilibrium selection in games with a patient player, Econometrica 57 (1989), 759-78. 
16. D. Fudenberg, and E. Maskin, The folk theorem in repeated games with discounting or with incomplete information, Econometrica 54 (1986), 533-54.

17. E. J. Green, and R. H. Porter, Noncooperative collusion under imperfect price information, Econometrica 52 (1984), 87-100.

18. H. I. Grossman, and J. B. Van Huyck, Sovereign debt as a contingent claim: Excusable default, repudiation, and reputation, Amer. Econ. Rev. 78 (1988), 1088-97.

19. F. E. Kydland, and E. C. Prescott, Rules rather than discretion: The inconsistency of optimal plans, $J$. Polit. Econ. 85 (1977), 473-91.

20. R. E. Lucas, Jr. and N. L. Stokey, Optimal fiscal and monetary policy in an economy without capital, J. Mone. Econ. 12 (1983), 55-93.

21. M. Persson; T. Persson; and L. E. O. Svensson, Time consistency of fiscal and monetary policy, Econometrica 55 (1987), 1419-31.

22. E. C. Prescott, Should control theory be used for economic stabilization?, in "Optimal Policies, Control Theory and Technology Exports," (K. Brunner and A. H. Meltzer, Ed.), pp. 13-38, Carnegie-Rochester Conference Series on Public Policy 7, North-Holland: Amsterdam, 1977.

23. F. P. Ramsey, A contribution to the theory of taxation, Econ. J. 37 (1927), 47-61.

24. C. A. Rogers, Debt restructuring with a public good, photocopy, Georgetown University, 1987.

25. N. L. Stokey, Reputation and time consistency, Amer. Econ. Rev. 79 (1989), 134-39.

26. M. L. Weitzman, Duality theory for infinite horizon convex models, Manage. Sci. 19 (1973), 783-89.

27. P. Whittle, “Optimization Over Time: Dynamic Programming and Stochastic Control II," Wiley: New York, NY, 1983. 